\title{
Post-Translational Modifications of Nuclear Proteins in the Response of Plant Cells to Abiotic Stresses
}

\author{
Jennifer Dahan 1,2,3, Emmanuel Koen ${ }^{1,2}$, Agnès Dutartre1,2, \\ Olivier Lamotte1,2 and Stéphane Bourque ${ }^{1,2,4}$ \\ ${ }^{1}$ Université de Bourgogne, UMR Plante-Microbe-Environnement \\ Dijon cedex \\ ${ }^{2}$ UMR 1088 INRA - 5184 CNRS \\ Dijon cédex \\ ${ }^{3}$ Institut Jean-Pierre Bourgin, INRA Centre de Versailles-Grignon \\ Versailles Cedex \\ France
}

\section{Introduction}

For a long time, in plant cells as in animal cells, the nucleus was only considered as the organelle in which fundamental mechanisms such as replication and transcription occurred. While strong efforts were deployed in order to identify important families of transcription factors such as MYB, WRKY or TGA families (Dubos et al., 2010; Rushton et al., 2010), a few attention was devoted to our lack of knowledge about their regulation in regard to the physiological conditions of the plant cells. Whereas the major importance of posttranslational modification of proteins is well established for several decades regarding cytosolic proteins, the last years have been characterized by the discovery that the plant cell nucleus also contains all the enzymes necessary to assume these fundamental reactions in terms of signal transduction. For example, Mitogen-Activated Protein Kinases (MAPK) are well known protein kinases (PKs) involved in response to both biotic and abiotic stresses (for review see Dahan et al., 2009). These MAPKs play a crucial role in the regulation of specific gene expression by phosphorylating particular transcription factors. However, while they are well described in the cytosol, only recently researchers focused on their presence and involvement in the nucleus of plant cells challenged by abiotic stresses (for example, Ahlfors et al., 2004). Unfortunately, these authors like the other ones involved in plant cell nucleus studies did not try to identify the targets of these MAPK. This example highlights the fact that our knowledge of the incidence of protein posttranslational modifications regarding the cellular activities is still poorly rudimental, and particularly in the field of abiotic stress responses.

Amongst the targets of these post-translational modifications, histones will be a piece of choice, being one of the favourite substrates for acetylation or methylation for example. Histones are small basic protein associated with DNA to form the chromatin. Chromatin 
contains histone octamere composed by two copies of each histone $\mathrm{H} 2 \mathrm{~A}, \mathrm{H} 2 \mathrm{~B}, \mathrm{H} 3$ and $\mathrm{H} 4$ to form the histone core. Histones composing the histone core are extremely conserved in the different kingdoms. For example, histone $\mathrm{H} 3$ differs only by two amino acids in its sequence in rat and pea. The histone core is rolled by approximately 146 bps of DNA to form a nucleosome, the repeating unit of chromatin which provided a first level of DNA compaction. Association of nucleosome with other protein like histone $\mathrm{H} 1$ creates a structure named $30 \mathrm{~nm}$ chromatin fiber (Kornberg and Lorch, 1999; Hayes and Hansen, 2001). This fiber can be unfold by several protein grouped under the term chromatin remodeling complex to generate a $11 \mathrm{~nm}$ fiber, the template for transcription. The $11 \mathrm{~nm}$ fiber can also be repressive to transcription process but different types of protein complexes can affect the chromatin to modulate DNA accessibility to transcriptional machinery and at the end gene transcription. Histone tails and globular domains are subjected to a variety of posttranslational modifications such as acetylation, methylation, phosphorylation, ubiquitination, sumoylation, ADP ribosylation, deimination and proline isomerization. These covalent modifications of histones are important in chromatin dynamics (Kouzarides, 2007). It has been proposed that all the histone postranslationnal modifications constitute a code, "the histone code" associating to all the possible combinations of modification a particular state allowing biological process such as transcription of gene. This code is written by particular proteins: "the writers", interpreted by other proteins: "the readers" and erased by a last class of protein, "the erasers" (Figure 1). Readers could also be able to modify histones or to recruit other protein actin on chromatin (Strahl and Allis, 2000).

The goal of this book chapter is to summarize our current knowledge of the molecular actors and their regulations that lead to posttranslational modifications of nuclear proteins, and in fine to the regulation of specific target gene expression. For this purpose, a large number of nuclear enzymes that are involved in (de)phosphorylation, (de)acetylation, and (de)methylation of nuclear proteins, but also in nuclear protein degradation pathway associated with sumoylation and ubiquitination, and in changes of the redox state of the nuclear proteins will be presented and their roles illustrated by various but non exhaustive cell responses to abiotic stresses.

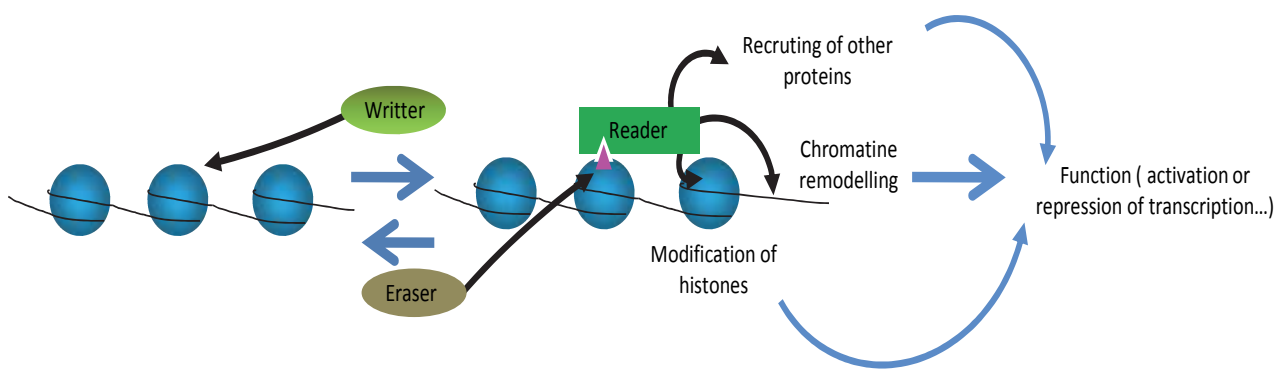

Fig. 1. Schematic representation of histone code. Writers can recognize chromatin area and add marks on histone (methylation, acetylation...). Theses labeling is dynamic because marks can be remove by erasers. They can also be recognized par readers, another group of proteins able to act directly or indirectly on chromatin structure. The final consequence can be a modification of the gene transcription in concerned loci. 


\section{Nuclear protein phosphorylation / dephosphorylation}

Phosphorylation is probably the most prominent and major posttranslational modification in living organisms. This reversible modification consists on the covalent binding of a phosphate on aminoacids hydroxyl residues. In eukaryotes, phosphorylation occurs mainly on Ser, Thr and Tyr residues. This modification depends on the action of two types of enzymes with antagonistic activities: (i) PKs which phosphorylates and (ii) protein phosphatases (PPs) which remove phosphoryl groups from target proteins. The binding of the phosphoryl group alters the functional properties of target proteins in terms of activity, subcellular localization, protein-protein interactions or stability (Cohen, 2000). This versatility has made phosphorylation one of the major means for modulation of cellular activities, as phosphorylation status can be finely tuned as the result of the balance between PKs and PPs activities at a given time point on specific substrates. These enzymes are thus involved at every steps of signal transduction, from plasma membrane to final effectors. Although numerous studies like the ones regarding brassinosteroids, have investigated PKs, PPs and their targets in the plasma membrane and the cytoplasm (Li, 2005), only few ones has focused on those localized, temporarily or permanently, in the nuclear compartment, despite their involvement in critical processes for cell surviving (Dahan et al., 2009). A recent phosphoproteomic analysis of the nuclear proteins from Arabidopsis thaliana showed that the identified phosporylated proteins cover a wide range of nuclear activities, indicating an equal importance of phosporylation in the modulation of nuclear activities as for the cytoplasmic ones (Jones et al., 2009).

In plants, PKs constitute a superfamily of proteins, and according to their importance in cellular homeostasis, it was shown that around $4 \%$ of $A$. thaliana genome encodes putative PKs (Champion et al., 2004). According to their substrate specificities, PKs and PPs can be classified into three families: (i) Ser/Thr PKs/PPs, (ii) Tyr PKs/PPs and (iii) dual-specificity (Ser/Thr-Tyr) PKs/PPs. In plants, no functional Tyr PK has been described to date, although predicted (Miranda-Saavedra and Barton, 2007). Consistent with this, the relative abundance of phosphor-Ser, phosphor-Thr and phosphor-Tyr has been estimated in $A$. thaliana to $85 \%, 11 \%$ and $4 \%$ respectively (Sugiyama et al., 2008). Although Tyr (de)phosphorylation is thus accomplished through dual-specificity PKs/PPs, to date, the vast majority of studies have been focused on Ser/Thr PKs/PPs in plant.

More than half of the putative PKs from the A. thaliana genome fall in the clade of the socalled Receptor-Like protein Kinases (RLKs), which are transmembrane proteins probably acting as receptors of environmental stimuli (Tör et al., 2009). The other part of plant PKs, which is of interest in this article, constitutes the clade of the "soluble" ones, and concerns all PKs found in the cytoplasm and the nucleus. This clade can be divided into numerous families and subfamilies, based on sequence similarities of the kinase domain and features of flanking sequences determining regulation properties (Hanks and Hunter, 1995; Champion et al., 2004; Miranda-Saavedra and Barton, 2007); readers are invited to report to these works for more details). Although for a large part studied in the cytoplasm or at the plasma membrane level, members from almost all families have been found in the nuclear compartment (for a detailed review, see Dahan et al., 2010). The majority of the available data on these nuclear PKs comes from subcellular distribution studies. Indeed for most of them their nuclear localization has been investigated using chimerical PKs fused to a fluorescent reporter, or immunolocalization studies based on specific antibodies. The 
activity of the PKs in the nucleus has only been assessed in rare cases, impairing our understanding of their roles and functionality.

While the core catalytic domain of PKs derived from a single ancestor (Hanks and Hunter, 1995), PPs origins are more diversified (Moorhead et al., 2009). In plants, around 160 sequences coding for putative catalytic subunit of PPs have been retrieved (Kerk et al., 2002). They can be divided in three main families, based on catalytic domain sequences and enzymatic features: (i) the PPP (phophoprotein phosphatase) family, (ii) the PPM (metallodependent protein phosphatase) family, and (iii) the PTP (phosphotyrosine phosphatase) including the DSP (dual-specificity phosphatase). Readers are invited to refer to other reviews that detailed the features of these families (Kerk et al., 2002; Luan, 2003; Moorhead et al., 2009). As for plant PKs, PP functionalities in the nucleus have been poorly studied.

The role of several nuclear PKs in response to different abiotic stresses has been investigated in different model plants. To date, and despite the great diversity of PKs, only a few families have been shown to be involved in these signaling pathways at a nuclear level. Among them, the MAPK family is certainly the most studied family of PKs in the nucleus. MAPK is the last component of a cascade of three PKs, which are sequentially activated (Widmann et al., 1999). The perception of an environmental stimulus drives the activation of the first PK of this transduction module, namely MAPKKK (MAPK kinase kinase). MAPKKK in turn activates by phosphorylation on a specific motif a MAPKK (MAPK kinase), which phosphorylates MAPK, the final effector, on conserved residues. This chain of phosphorylation is thought to take place in the cytoplasm, and the MAPK is then translocated upon activation by phosphorylation into the nucleus, where it modulates gene expression by acting on transcription factors. However the presence of MAPKK and MAPKKK in the nucleus was already reported (Dahan et al., 2009).

Figure 2 illustrates, although partially, the known nuclear PKs that were shown to be involved in response to various abiotic stresses. Even though MAPK was involved in the response to many abiotic stresses on the basis of their activation in the cytosol, few of them have been demonstrated to localize and to act in the nuclear compartment. In fact in the context of abiotic stresses only one study showed the translocation in A. thaliana of two MAPKs, AtMPK3 and AtMPK6, following ozone exposure and using immunolocalization of the native protein (Ahlfors et al., 2004). However contradictory results were obtained when these two MAPKs were expressed fused to GFP, and showed a constitutive nuclear and cytoplasmic localization (Yoo et al., 2008). In addition to ozone exposure, these two MAPKs are furthermore activated in response to several abiotic stresses, such as cold, salt, drought, wounding and touch for AtMPK6 (Ichimura et al., 2000) and osmotic stress for AMPK3 (Droillard et al., 2002). The orthologs of AtMPK3 and AtMPK6 in tobacco, respectively WIPK (Wounding-Induced Protein Kinase) and SIPK (Salicylic acid-Induced Protein Kinase), are also activated in response to several environmental cues, such as high salinity and osmotic stresses, wouding and ozone exposure (Zhang and Klessig, 1998; Mikolajczyk et al., 2000; Samuel and Ellis, 2002). They were shown to be nuclear, independently of any stimuli when fused to GFP (Menke et al., 2005; Yap et al., 2005), and the activity of SIPK could be retrieved in nuclear extracts of osmotically stressed tobacco cells (Dahan et al., 2009), demonstrating its functionality in the nuclear compartment in response to environmental stresses.. A few substrates of MAPKs have been identified, and so their precise roles in response to abiotic stresses remain elusive. For the most part, their known targets are transcription factors. For example, SIPK was shown to phosphorylate in vitro the transcription factor WRKY1, involved in the expression of defense-related genes (Menke et al., 2005). This suggests that 
MAPKs, in response to different abiotic stresses, could be involved in the reprogramming of transcription patterns to allow the plant to cope with the perceived stresses. Given that, the overexpression or knock-out of several MAPKs impairs the outcome of the response to some abiotic stresses. The extinction of Atmpk6 expression using RNAi and a loss-of-function mutation of Atmpk3 both generate increased sensitivity to ozone leading to cell death, implying that these MAPK play an important role in the management of ozone stress by $A$. thaliana (Ahlfors et al., 2004). Another A. thaliana MAPK, AtMPK4, has been shown to reside permanently in the nucleus along with the cytoplasm (Andreasson et al., 2005; Kosetsu et al., 2010). Although more studied for its potential role in cytokinesis (Kosetsu et al., 2010) and its involvement in plant defense reactions (Andreasson et al., 2005; Gao et al., 2008), its activity is observed upon application of stresses such as cold, salt and osmotic stresses (Droillard et al., 2004; Teige et al., 2004). One substrate for this MAPK has been described in vitro: MKS1, which is a protein interacting with two WRKY transcription factors (Andreasson et al., 2005). The phosphorylation of MKS1 by AtMPK4 is thought to result in the release of the WRKY33, which could then play its role as a transcriptional regulator (Qiu et al., 2008). However, this interaction takes place in the context of defense reaction, and no data is available regarding functionality of AtMPK4 in response to abiotic stresses.

\begin{tabular}{|c|c|c|}
\hline Stress & Kinase/phosphatase & HDAC/HAT \\
\hline Cold & $\begin{array}{l}\text { MPK6 (Ichimura et al., 2000) } \\
\text { MPK4 (Droillard et al., 2004; Teige et al., } \\
\text { 2004) }\end{array}$ & $\begin{array}{l}\text { AtGCN5/HAG1 (Servet et al., } \\
\text { 2010) } \\
\text { HDA18, HDA19 (Alinsug et al., } \\
\text { 2009) } \\
\text { SIR2 (Bond et al., 2009) }\end{array}$ \\
\hline Heat & & HDA7 (Alinsug et al., 2009) \\
\hline Salt & $\begin{array}{l}\text { MPK6 (Ichimura et al., 2000) } \\
\text { SnRK2 (Halford and Hey, 2009) } \\
\text { MPK4 (Droillard et al., 2004; Teige et al., } \\
\text { 2004) }\end{array}$ & $\begin{array}{l}\text { HDA6 (Chen et al., 2010) } \\
\text { HDA19 (Chen and Wu, 2010) } \\
\text { HDA2, HDA14 (Alinsug et al., } \\
\text { 2009) } \\
\text { HD2C (Sridha and Wu, 2006) }\end{array}$ \\
\hline Osmotic & $\begin{array}{l}\text { MPK3 (Droillard et al., 2002) } \\
\text { MPK4 (Droillard et al., 2004; Teige et al., } \\
\text { 2004) } \\
\text { SnRK2 (Halford and Hey, 2009) }\end{array}$ & \\
\hline Drought & $\begin{array}{l}\text { MPK6 (Ichimura et al., 2000) } \\
\text { SnRK2 (Halford and Hey, 2009) }\end{array}$ & \\
\hline Light & & $\begin{array}{l}\text { HDA19 (Tian et al., 2003) } \\
\text { HDA7 (Alinsug et al., 2009) } \\
\text { GCN5 (Benhamed et al., 2006) }\end{array}$ \\
\hline Ozone & MPK3, MPK6 (Ahlfors et al., 2004) & \\
\hline Wounding & MPK6 (Ichimura et al., 2000) & HDA19 (Zhou et al., 2005) \\
\hline
\end{tabular}

Fig. 2. An overview of nuclear enzymes involved in phosphorylation/dephosphorylation or acetylation/deacetylation processes in response to various abiotic stresses. 
Not only MAPKs are the nuclear crossroads of abiotic stresses. Data that are piling up to put PKs and PPs at the centre of the regulation of the adaptative reponses of plant cells to osmotic, saline and hydric stresses, in link with ABA (abscisic acid), point out the role of other nuclear PK. In particular SnRK2 (for Snf1-Related protein Kinase) family is constituted of PKs initially characterized as ABA signalling factors. They can be categorized into three subclasses, and subsequent studies on rice and A. thaliana PKs demonstrated that all of the subclasses could be activated in response to osmotic stress, with subclasses II and III being also responsive to ABA (Halford and Hey, 2009). ABA is a phytohormone essential for the establishment of adaptative responses to drought and salinity stresses. Its accumulation leads to expression of ABA-responsive genes helping cells to cope with hydric and osmotic variations (Hubbard et al., 2010). It was recently shown that at the heart of its signalling pathway in A. thaliana is a core complex composed of three subclass III SnRK2 called SnRK2D, E and I, and their cognate PPs PP2C. Indeed SnRK2s are rendered active upon phosphorylation on two critical residues in their activation loop (Belin et al., 2006; Burza et al., 2006; Boudsocq et al., 2007). Recently, several PPs from the PP2C family have been shown to dephosphorylate these residues, thus inactivating the PKs. These partners have been colocalized in the nuclear compartment, where they interact in permanence (Umezawa et al., 2009). Interestingly, the same SnRK2s were also shown to associate in the nucleus with AREB1, a transcription factor whose expression occurs during drought (Fujii et al., 2009). A triple mutant plant impaired in the expression of SnRK2D, E and I exhibited a strongly reduced tolerance to drought, comforting the involvement of these PKs in response to water shortage. Accordingly, drastic changes was observed in response to ABA, high salinity stress and drought at the transcriptional level, with down-regulation of ABA responsivegenes as compared to wild type plants (Fujita et al., 2009). Upon perception, water and osmotic stresses lead to production of ABA which in turn activates the transduction module composed of the PP2Cs and the SnRK2s. The signaling pathway is then achieved by phosphorylation of specific transcription factors, controlling a set of stress and ABAresponsive genes. Likewise, other SnRK2s have been characterized in several plant species that can phosphorylate ABA-responsive transcription factors. In wheat, the SnRK2 PKABA1 has been shown to interact with and phosphorylate in vitro TaABF, an ortholog of AREB1 (Johnson et al., 2002). Furthermore, three rice SnRK2s were found to phosphorylate and activate another ortholog of AREB1, TRAB1 (Kobayashi et al., 2005). However in the last two cases, the subcellular partitioning of the PK was not investigated. Recent data suggest that the transduction module composed of the SnRK2 and PP2C could be directly activated in the nucleus, meaning that the $\mathrm{ABA}$ receptor is expected to translocate after binding to its ligand.

Calcium is a well recognized second messenger, and as such its variations in the cytosol specifically induced by many stimuli promote specific signal transduction through decoding by a panel of $\mathrm{Ca}^{2+}$ sensor molecules (Kudla et al., 2010). It is now well established that apart from the cytosol, nucleus is able to generate its own $\mathrm{Ca}^{2+}$ signatures following diverse environmental cues (Mazars et al., 2009). Accordingly, $\mathrm{Ca}^{2+}$-binding proteins have been localized in the nucleus, where they can decode $\mathrm{Ca}^{2+}$ variations into an appropriate response, like modulation of the expression of specific set of genes (Xiong et al., 2006). Accordingly, several PKs and PPs potentially regulated by $\mathrm{Ca}^{2+}$ have been localized in the nucleus, where they are thought to decode nuclear $\mathrm{Ca}^{2+}$ variations into modifications of phosphorylation state of specific target proteins. The concerned PKs are mainly CDPKs 
(Ca ${ }^{2+}$-Dependent Protein Kinases) and CIPKs (Calcineurin B-like[CBL]-Interacting Protein Kinases). CDPKs are specifics to plant and exhibit in their sequence a CaM-like domain with three to four EF-hand $\mathrm{Ca}^{2+}$ binding motifs, rendering them directly dependent on $\mathrm{Ca}^{2+}$ binding for their activities (Klimecka and Muszynska, 2007). A study on the subcellular targeting performed for 9 of the 34 putative CDPK in A. thaliana showed that two of them, AtCPK3 and AtCPK4 are constitutively cytosolic and nuclear (Dammann et al., 2003). AtCPK3 has been shown to be activated at the plasma membrane level following a salt stress, and in accordance to this putative involvement knock-out Atcpk3 mutant plant exhibited altered resistance to salt stress, whereas it was improved in Atcpk3 overexpressor mutant line (Mehlmer et al., 2010). Intriguingly, no transcriptional changes in the expression of traditionally salt-stress related genes were observed, raising the question of AtCPK3 nuclear role (Mehlmer et al., 2010). Apart salt stress, another CDPK, AtCPK32, has been found to be involved in ABA signaling, through interaction and phosphorylation with an ABA-responsive transcription factors, ABF4. Interestingly these two proteins are colocalized in the nucleus (Choi et al., 2005). Whereas most of the CDPK studied show a constitutive partitioning between different sublocation and the nucleus, two CDPK from different species are suggested to translocate from the plasma membrane to the nucleus upon stresses. McCPK1 from Mesembryanthemum crystallinum is transcriptionnaly induced following salt- or water deficit stresses and when fused to GFP, translocate from the plasma membrane to the nuclear compartment (Chehab et al., 2004). However the mechanisms and the functions of this phenomenon are not explained to date. Even if CDPKs are thought to have their activities regulated by $\mathrm{Ca}^{2+}$ concentrations in the cytosol (Harmon, 2003), recent data suggest that they could also be part of phosphorylation cascade, as for NtCDPK2 and $\mathrm{NtCDPK} 3$, complicating conventional signaling schemes (Witte et al., 2010). Despite recent advances in the understanding of the functionality of $\mathrm{Ca}^{2+}$ variations, the ion still constitute a missing when it comes down to evaluate its part in the activation of specific signaling pathways.

\section{Nuclear protein acetylation / deacetylation}

The first descriptions of a nuclear protein modification by the chemical binding of an acetyl group on the amine function of lysine residues was observed on histone proteins (Allfrey et al., 1964), explaining why enzymes responsible for the acetylation and deacetylation processes were named histone acetyltransferases (HATs; Gallwitz, 1971) and histone deacetylases (HDACs; Inoue and Fujimoto, 1969), respectively. However, based on their ability to act on proteins unrelated to histone such as transcription factors or coregulators of gene transcription, HATs and HDACs are more generally considered as lysine acetyl transferases and lysine deacetylases (Chen and Tian, 2007). All these proteins were reported to be located, exclusively or not, into the nucleus of plant cell.

\subsection{Histone deacetylases (HDACs)}

Concerning HDACs, plant genomes contain members that belong to two different families that are common to eukaryotes (Pandey et al., 2002): the RPD3 (Reduced Potassium Dependency Protein 3) - HDA1 (Histone Deacetylase 1) superfamily, and SIR2 (Silent Information Regulator 2) family. The third family, termed HD2 (type-2 Histone Deacetylase), is specific to plant cells (Fu et al., 2007). 
The first member of the RPD3-HDA1 superfamily was identified in yeast in a complementation screen of a mutant for a high affinity potassium transporter (Vidal et al., 1990). It was latter shown that RPD3 encodes the catalytic subunit of the HDB (Histone Deacetylase B) complex activity (Rundlett et al., 1996). The first plant RPD3-HDAC member, ZmRpd3, was identified in maize thanks to its ability to functionally complement a yeast rpd3 null mutant (Rossi et al., 1998). Among the eleven RPD3 genes identified in the maize genome, three of them (ZmHDA101, ZmHDA102 and ZmHDA108) exhibit the same expression pattern, suggesting a possible functional redundancy among this gene family (Varotto et al., 2003). In term of specificity, ZmRPD3s, like its counterpart in yeast, seem to specifically remove the acetyl tail of lysines of histone $\mathrm{H} 4$ (H4K5, H4K12) prior to its incorporation in chromatin (Lechner et al., 2000). Homologs of ZmRPD3 were also identified in A. thaliana and classified in three different clades : Class I for the RPD3 group, Class II for the HDA1-like group, and Class IV for the AtHDA2 group (Alinsug et al., 2009). Whereas 18 RPD3-like genes were identified from the genome analysis data, only AtHD1 (also called AtHDA19 or RPD3A) and AtHDA6 were largely characterized. AtHD1, that is constitutively expressed, encodes a protein that localises both in the cytoplasm and in the nucleus, but is predominantly accumulated in the euchromatic region and excluded from the nucleolus (Varotto et al., 2003; Fong et al., 2006). AtHD1 exhibits a histone deacetylase activity that removes the acetyl group of histone $\mathrm{H} 3$ (H3K9) and H4 (H4K5, H4K8, H4K12, H4K16; Tian et al., 2003). AtHDA6, although it is the close homolog of AtHD1, exhibits major differences in term of expression and specificity. AtHDA6 is largely accumulated in the nucleoli (Probst et al., 2004) and is a broad-specificity HDAC that removes the acetyl group of various lysines of histone H3 and H4 (H3K14, H4K5, H4K12; Earley et al., 2006). In agreement with these differences in their expression profiles, AtHD1 and AtHDA6 are involved in different signalling pathways: AtHD1 regulates several developmental processes such as early senescence, floral organ identity or late flowering (Wu et al., 2000; Tian and Chen, 2001; Tian et al., 2005), by controlling the expression of a set of genes involved in protein synthesis, ionic homeostasis or plant hormonal regulation (Tian et al., 2005). AtHDA6, due to its localisation in the nucleolus, is involved in the inhibition of the NORs (nucleolus organisation region; Probst et al., 2004; Earley et al., 2006), and evidences supporting roles in silencing transgenes and transposons were also reported (Murfett et al., 2001; Aufsatz et al., 2002; Lippman et al., 2003; May et al., 2005). In a structural point of view, a huge study was conducted with the RPD3-like HDACs of A. thaliana (Alinsug et al., 2009). All members are characterized by a variable catalytical domain characterized by a pocket that can either bind a $\mathrm{Zn}^{2+}$ cation necessary to ensure the deacetylation reaction, or different inhibitors like sodium butyrate or trichostatine A (Finnin et al., 1999). Different members of this family like HDA6, HDA7 or HDA19 contain a NLS and / or NES, confirming the nuclear localisation of these enzymes, but also that a cytosolic / nuclear shuttling could be of importance for their mode of action.

Several studies, mainly based on the use of mutants in RPD3-HDA1 A. thaliana genes, have reported that they play major roles in various biotic and abiotic stress responses (Figure 2; Alinsug et al., 2009). Amongst the 18 HDAC A. thaliana genes belonging to the RPD3-HDA1 family, most of them appear to be partly or largely involved in response to various environmental stresses. For example, in the Class I RP3-HDAC, AtHDA19 that is the best characterized member of this family, is highly expressed in germinating and imbibed seeds and also strongly accumulated in response to cold stress (Alinsug et al., 
2009), wounding (Zhou et al., 2005) or light response (Tian et al., 2003; Tian et al., 2005). In fact, Tian et al. (2005) showed that approximately $7 \%$ of the Arabidopsis genome is up- or down-regulated in athda19 mutants. For example, Tian et al. (2003) showed that hda19 mutant lines were affected in their flowering process under long day conditions, exhibiting the opposite phenotype of mutants altered in the expression of the histone acetyltraferase GCN5. Interstingly, the double mutant gcn5:hda19 is characterized by a normal phenotype in response to light, suggesting that both HDA19 and GCN5 could target the same genes. This was shown by Benhamed et al. (2006): a reduced histone acetylation was monitored in the promoter of $C A B 2, R B C S-1 A$ and IAA3 genes in the gcn 5 mutants, whereas an increase histone acetylation was observed in the promoter of the same genes in the hda19 mutants. Furthermore AtHDA19 expression is strongly induced in response to wounding and the stress related hormons JA and ethylene, suggesting that it could be involved in many abiotic stresses leading to the production of both compounds (Zhou et al., 2005). AtHDA19 was also reported to be involved in response to abiotic through its interaction with the transcription corepressor LEUNIG by repressing gene transcription (Gonzalez et al., 2007). In the same way, overexpression of AtHDA19 in Brassica napus demonstrated that it was involved in response to cold stress by interacting with bnKCP1, a novel protein containing a putative kinase-inducible domain (Gao et al., 2003).

AtHDA6, another RPD3-type histone deacetylase in A. thaliana, is involved in response to ABA and salt stress. Chen et al. (2010) showed that an AtHDA6 mutant, axe1-5, as well as HDA6 RNA-interfering plants are hypersensitive to salt and ABA treatment, due to the down-regulation of various abiotic stress responsive genes like $A B I 1, A B I 2, R D 29 A$ or $R D 29 B$. This hypersensitivity to salt stress is correlated with changes in $\mathrm{H} 3$ acetylation pattern. Without ABA treatment, an increase of $\mathrm{H} 3$ acetylation was shown both in the promoter and in exons of these genes in the axe1-5 mutant compared to Col0. In response to $\mathrm{ABA}$, an increase of $\mathrm{H3}$ acetylation was only monitored in Col0 but not in the axe1-5 mutant, indicating that HDA6 is required for the induction of acetylation by ABA and salt treatment. A similar phenotype was obtained with the A. thaliana HDA19 T-DNA insertion mutant, hda19-1 (Chen and Wu, 2010). On the contrary, other RPD3 HDAC like AtHDA7 are not differentially expressed in regard to developmental stages but are induced in response to both biotic (Pseudomonas syringae) and abiotic stimuli such light intensity or heat stress, according to microarray data analyses (Alinsug et al., 2009).

Little information is available regarding the properties of HDA1-like HDACs in plants. The study of one member of this family in maize, ZmHDA1, reported that it is expressed in an inactive form of high molecular weight $(84-\mathrm{kDa})$ that needs to be processed in an active form of $48-\mathrm{kDa}$ by a proteolytic cleavage of the C-terminal end to regulate gene transcription (Pipal et al., 2003). According to the data of the sequenced genomes, A. thaliana contains five members of the HDA1 group also termed class II. Members of this Class II are also involved in response to various environmental stresses: while heat stress seems to upregulate most of the Class II HDAs, $\mathrm{NaCl}$ treatment only stimulates AtHDA14 and AtHDA2 expression (Alinsug et al., 2009). Furthermore, AtHDA18 expression is induced in response to cold treatment. Demetriou et al. (2009) reported that members of this HDAC family in Barley are also regulated by JA in response to abiotic stresses: whereas HvHDAC1-I-1 is slightly reduced after $6 \mathrm{hr}$ of treatment, other genes like HvHDAC1-II-1 or HvHDAC1-IV-1 are strongly accumulated after $6 \mathrm{hr}$. 
The SIR2-like HDACs are characterised by their NAD-dependent histone deacetylase activity. They are homolog to the yeast SIR2 HDAC that is involved in longevity (Imai et al., 2000). Although the genome of all sequenced plants contains several Sir2-like genes, their functions are yet to be determined. A recent study in A. thaliana showed that AtSIR2 regulates several defence related genes involved in the synthesis of SA, implying potentially SIR2 members in plant defence reactions (Wang et al., 2010). To our knowledge, only one study recently reported the involvement of SIR2 in response to low temperature in the context of vernalization (Bond et al., 2009). SIR2 class of HDAC would repress the expression of the MADS box transcription factor FLC (for Flowering Locus C, a central gene in the vernalization process) by altering the acetylation pattern of histones $\mathrm{H} 3$ and $\mathrm{H} 4$.

The last HDAC family, termed HD2-like, is specific to plants and do not share any sequence similarities with other HDAC proteins (Pandey et al., 2002). Three genes HD2 HDAC genes /or homologues are coded in maize genome, four in A. thaliana, two in rice and in barley. All HD2 display similarities with the FKBP family peptidyl-propyl cis-trans isomerase (Aravind and Koonin, 1998; Dangl et al., 2001) and display the same architecture: a conserved EFWG motif in the N-terminal region that comprises the catalytical domain, a central acidic domain involved both in enzymatic activity and its regulation, and in the Cterminal part a NLS and a $\mathrm{Zn}^{2+}$ finger that may be involved in protein/protein or protein/DNA interactions. Several members of this family like ZmHD2 in maize and AtHD2A in A. thaliana were shown to be localized in the nucleolus and to deacetylate the lysine 9 of histone H3, suggesting that they should be involved in the regulation of ribosomal RNA expression (Lusser et al., 1997; Earley et al., 2006). However their mode of action is still largely unknown; they seem to be mainly involved in plant defence reactions (Bourque et al., 2011) and in seed development (Wu et al., 2000). In A. thaliana, Sridha and $\mathrm{Wu}$ (2006) showed that overexpression of AtHD2C enhances tolerance to salt stress and drought compare to wild-type plants by affecting the expression of several abscisic acidresponsive genes. However, we do not know whether or not it affects the acetylation of these genes.

\subsection{Histone acetyltransferases (HATs)}

The action of the HDAC proteins is reversed by the one of the HATs that catalyse the transfer of an acetyl group from acetyl SCoA to the amine function of a lysine residue, particularly in histone proteins (Servet et al., 2010). Like HDACs, HATs are divided into several groups based on primary homology with yeast and mammalian HATs: GNAT (for GCN5-related N-acetyltransferase), MYST (for MOZ, Ybf2/Sas2 and Tip60), p300/CBP (for CREB-binding protein) and TAF1 (for TATA-binding protein (TBP)-associated factor 1) groups. The GNAT group is usually subdivided into three subfamilies termed GCN5 (for General Control Nonderepressive protein 5), ELP3 (for transcriptional ELongator complex Protein 3) and HAT1. In a structural point of view, HATs are usually constituted by two fundamental domains: the catalytical acetyltransferase domain, and the bromodomain. The bromodomain is composed of 110 aminoacids that can bind to acetylated lysine residues (Owen et al., 2000). Bromodomains are generally found in proteins that regulate chromatin structure and gene expression, such as HATs and the ATPase component of certain nucleosomes-remodeling complexes. The mode of recognition of acetyl-lysine by the bromodomain is similar to the one of acetyl SCoA by HATs, since the bromodomain is the only domain known to interact with acetylated lysine containing peptides. Among the 
different HATs expressed in A. thaliana, AtGCN5/HAG1, which belongs to the GNAT HAT family, is one of the best characterized in terms of function and is involved both in abiotic and developmental responses (see Servet et al., 2010 for a recent review). Regarding its specificity, the major targets of this HAT are histone H3 (H3K9, H3K14, H3K18 and H3K27) and histone H4 (H4K5, H4K8, H4K12 and H4K16; Zhang et al., 2007). The bromodomain of AtGCN5, that was shown to bind to acetylated histone lysine motifs, is probably not required for its binding to most of its targets (Benhamed et al., 2008). Among its targets, in addition to histones $\mathrm{H} 3$ and $\mathrm{H} 4$, AtGCN5 also interacts and acetylates other proteins such as AtADA2 that could regulate HAT activity (Servet et al., 2010). Furthermore, AtGCN5 activity could be regulated by phosphorylation/dephosphorylation, since it interacts with protein phosphatase $2 \mathrm{C}$ in vitro and mutation in PP2C gene increases $\mathrm{H} 3 \mathrm{~K} 14$ acetylation, one of the targets of AtGCN5. The other HAT proteins are less characterized in terms of target and mode of action.

Works in the group of D.X Zhou have shown that AtGN5 is required for light-regulated gene expression by promoting the acetylation of the promoter of target genes (Benhamed et al., 2006; Benhamed et al., 2008; Servet et al., 2010). Several studies reported that abiotic stresses involve the association/regulation of HAT activities with various proteinaceous partners in the regulation of specific genes leading to the establishment of the biological response. For example, the GCN5 HAT is known to physically interact with the transcriptional coactivator Ada2 (Stockinger et al., 2001), this one enhancing the ability of GCN5 to acetylate histones in vitro and enabling GCN5 to acetylate nucleosomal histones (Mao et al., 2006). Hark et al. (2009) showed that mutants of one of both ADA2 genes, ADA2b, display hypersensitive phenotype to salt stress and altered responses to low temperature stress, a phenotype close to the one of AtGCN5 mutants. A recent study showed that ADA2b and GCN5 interact with a third partner, the coactivator SGF29a, to enhance the acetylation in the promoter region of target genes like COR6.6, RAB18, and RD29b (Kaldis et al., 2011). In the same vein, Gao et al. (2007) showed that AtGCN5 HAT activity is required in response to cold and stress treatment by its physical interaction with the transcription factor AtEML. The authors suggest that AtEML would co-ordinates the expression of target stress regulated genes through involvement in recruiting AtGCN5 to their promoters.

\section{Protein methylation}

Protein methylation involves transfer of a methyl group from S-adenosylmethionine (the universal methyl donor in cells) to acceptor groups on substrate proteins (Aletta et al., 1998). It commonly occurs on carboxyl groups of glutamate, leucine, and isoprenylated cysteine, or on the side-chain nitrogen atoms of lysine, arginine, and histidine residues (Clarke, 1993). In eukaryotes nuclei, one of the best known examples of protein methylation is probably histone methylation. Like acetylation, histone methylation is considerate as an important process regulating the chromatine dynamics and function (Strahl and Allis, 2000; Jenuwein and Allis, 2001; Zhang and Reinberg, 2001; Kouzarides, 2002). Histone methylation can occur at different residues and on distinct sites. For one residue, different numbers of methyl groups can be added. Even if some methylation has been characterized in the globular domain of H3 in animals (Feng et al., 2002), methylation seems to concern most of the time the N-terminal part of histones (named histone tail) (Bannister and Kouzarides, 2005). Histones methylation has been described mainly on histones $\mathrm{H} 3$ and $\mathrm{H} 4$ and occurs on both arginine and lysine residues. 


\subsection{Histone lysine methylations}

Lysine methylation consists on addition of one or more methylgroups to the $\varepsilon$-amino group of lysine residues, resulting in mono-, di-, or trimethylated lysine. Unlike acetylation, methylation of these residues does not change the charge but progressively increases the bulk and hydrophobicity. This may impact intra- or intermolecular hydrogen-bond interactions of the amino group or create new sites recognized by reader proteins that bind preferentially to the methylated domain (Lee et al., 2005). In eukaryotes, histone lysine methylation occurs on histone $\mathrm{H3}$ at lysines 4, 9, 14, 27, 36, and 79 and on histone $\mathrm{H} 4$ at lysines 20 and 59 (Strahl and Allis, 2000; Berger, 2002; Zhang et al., 2002; Zhang et al., 2003). A recent study provide evidences that methylation can also occurs on Lysine 37 of histone H2B in vivo (Gardner et al., 2011).

In A. thaliana, the best known histone lysine methylation occurs at Lys4 (K4), Lys9 (K9), Lys27 (K27), and Lys36 (K36) of histone H3 while methylation on lysine 20 of H4 has only been observed with immunostaining. Presence of methylation on H3 K79 which is highly conserved in non-plant systems has not been reported in plant. Methylations of lysine are catalyzed by HKMTs (histone lysine methyltransferases) that almost all share a SET [Su(var), Enhancer of zeste, trithorax] domain, a conserved motif containing approximately 130 amino acids which was originally identified in Drosophila. This domain is responsible for catalysis and binding of cofactor S-adenosyl-lmethionine (Lee et al., 2005). Plant genome encodes number of protein with set domain; for example, A. thaliana genome encodes 41 while grapes encode 32 and maize 37 (http://www.chromdb.org). Function of their homology with their Drosophila homologues E(Z), TRX, ASH1 and SU(VAR)3-9, they are assigned to four groups (Jenuwein et al., 1998). In A. thaliana, certain families of HKMTs seem to catalyse methylation on one particular site. It is the case for HKMTs homologues of SU(VAR)3-9 that are acting on H3K9 and for HKMTs relative to E(Z) that methylate H3K27. $\mathrm{E}(\mathrm{z})$ proteins are associated with other members in PRC2 (polycomb-group repressive complex 2) to performed H3K27 methylation. Members of other families seem to be able to act at different sites. It is the case of TRX homologue where different members can contribute to methylation of H3K4 or H3K27. Also ASH1 (for Absent, Small, or Homeotic discs 1) family seems to act on both H3K36 and H3K4. Nevertheless the link between this protein and histone methylation can be direct or indirect since methyl transferase activity has been not tested for all members of these different families (for review Liu et al., 2010). Methylated lysine can be then recognized by protein reader leading in a direct or indirect way to a particular function like gene silencing (Schotta et al., 2002; Jackson et al., 2004). These proteins comported domain that can recognized methylated lysine such as chromolike domains of the royal superfamily (including chromodomain, tudor domain, malignant brain tumor (MBT), PWWP, and plant Agenet module), or a plant homeodomain finger (PHD) or the WD40 repeat (Taverna et al., 2007). At this time only fews readers are known in plants and the way by which they translate the histone marks to direct downstream functions it is not fully understood.

\subsection{Stoechiometrie and localization of histone lysine methylation in plant}

In plants like in animals the three degrees of methylation (mono, di et trimethylation) on histone $\mathrm{H} 3$ at lysines 4, 9, 14, 27, 36 are found but proportions between the different degrees change. For example in A. thaliana, higher levels of H3K4 di-methylation (H3K4me2) and lower $\mathrm{H} 3 \mathrm{~K} 9 \mathrm{me} 2$ and $\mathrm{H} 3 \mathrm{~K} 9 \mathrm{me} 3$ levels have been detected compare to animals (Jackson et al., 
2004; Guo et al., 2006). Histones methylation profile has mainly be determined in A. thaliana thanks to Immunostaining of nuclei, chromatin immunoprecipitation (ChIP) , ChIP coupled with high-resolution microarray analysis (ChIP-chip) and mass spectrometry in combination with high-performance liquid chromatography (HPLC) separation methods (Liu et al., 2010). H3K4me1/2/3 are highly enriched in euchromatin in $A$. thaliana and about $90 \%$ of annotated genes carry one or more of the H3K4 methylation marks, suggesting an important role of this histone modification in the control of gene expression (van Dijk et al., 2010). H3K9 methylation is critical for maintenance of transcriptional gene silencing and genome stability (Vaillant and Paszkowski, 2007). H3K9me1 and H3K9me2 are predominant and enriched in heterochromatin (Johnson et al., 2004) while H3K9me3 is enriched in euchromatin (Mathieu et al., 2005; Turck et al., 2007). H3K9me2 is particularly present in transposons and repeated sequences according to the repressing transposon activities that have been attribute to this histone mark (Lippman et al., 2004; Bernatavichute et al., 2008). H3K27me1 and H3K27me2 are enriched in heterochromatin (Mathieu et al., 2005; Fuchs et al., 2006) while H3K27me3 is localized in euchromatin (Turck et al., 2007). H3K27me3 is found in about 4400 genes and is often localized upstream of promoters and of 5'UTR suggesting like for $\mathrm{H} 3 \mathrm{~K} 4$, an important role of this methylation in controle of gene expression in plant (Turck et al., 2007; Zhang et al., 2007). H3K36me1/3 are enriched in euchromatin while $\mathrm{H} 3 \mathrm{~K} 36 \mathrm{me} 2$ is present in both euchromatin and heterochromatin (Lin et al., 2008).

\subsection{Histones arginine methylation}

Arginine methylation can impact histone and more generally protein properties. In fact, arginine is a positively charged amino acid that has five potential hydrogen bond donors positioned for favorable interactions with biological hydrogen bond acceptors (Bedford and Clarke, 2009). These biochemical properties give to this amino acid a crucial role for protein structure and interaction with other molecules. In proteins interacting with DNA, arginine residues are the most frequent hydrogen bond donors to backbone phosphate groups and to thymine, adenine, and guanine bases (Luscombe et al., 2001). Protein arginine methylation results in the addition of one or two methyl groups to the guanidino nitrogen atoms of arginine (Gary and Clarke, 1998). Each addition of a methyl group to an arginine residue changes its form and removes a potential hydrogen bond donor (Bedford and Clarke, 2009). Since no protein able to interact with histone arginine methylation are known, it is possible that the only fact of methylate arginine is to impact interaction between histones and DNA, leading to an impact of chromatin structure and finally of gene expression.

In Eukaryotes, the best known arginine methylation concerned Arg2 (R2), Arg8 (R8), Arg17 (R17), Arg26 (R26) of histone H3, and Arg3 (R3) of histone H4. In A. thaliana, at this time only methylation on H4R3 and H3R17 have been detect in vivo. Protein arginine methylation is catalyzed by a family of protein named arginine methyltransferases (PRMTs). PRMTs are classified into four classes depending of the final methylated product of reaction that they can catalyze. Type I and type II enzymes are among others, involved in histone methylation and are one of the best characterized (Bedford and Richard, 2005). Both of them catalyze first addition of single methyl group on the terminal nitrogen atom of Arginine to form Mono methylated Arginine (MMA). Then, Type I PRMTs form asymmetric di-methylated Arg meaning that two methyl groups are added on the same nitrogen atom of the guanidine leading to an $\omega$-NG,NG-di-methyl arginine, while type II PRMTs performed symmetric 
dimethylation of Arg meaning that the two methyl groups are on two different nitrogen atome leading to an $\omega$-NG,N_G-d i-methyl arginine (Mitchell et al., 1992). A.thaliana genome codes for nine PRMTs (Niu et al., 2007). AtPRMT4a and AtPRMT4b, are homologs of human CARM1 and can performed asymmetrically H3R17me2a in vivo. H4R3 can be di-methylated symmetrically by AtPRMT5/SKB1 (Pei et al., 2007; Wang et al., 2007; Schmitz et al., 2008) and asymmetrically by AtPRMT1a, AtPRMT1b (Yan et al., 2007) and AtPRMT10 (Niu et al., 2007).

\subsection{Histones demethylation}

Histone methylation has been considered as irreversible until the discovery in 2004 of LSD1 (lysine-specific demethylase 1) in animals (Shi et al., 2004). This discovery proved that histone methylation is a dynamic process regulated by HMTs (the writers) but also histones demethylases (the erasers). Two types of demethylases exist with distinct mechanisms to remove lysine methylation: Flavin adenine dinucleotide (FAD)-dependent KDM1/LSD act by amine oxidation and need the cofactor Flavin adenine dinucleotide. JmjC domain-containing proteins act by hydroxylation and most of them use Fe(II) and a-ketoglutarate (Shi et al., 2004; Tsukada et al., 2006). These two classes of enzymes act on different substrates: Flavin adenine dinucleotide (FAD)-dependent KDM1/LSD1 are able to demethylate mono and dimethylation while JmjC domain-containing proteins demethylase act one mono-di and tri methylated lysines (Klose and Yi, 2007). In A. thaliana, potential histone demethylases have been predicted based on conservation of cofactor-binding amino acids ( $\mathrm{Lu}$ et al., 2008). There are four KDM1/LSD1 homologs in A. thaliana and one of them, LDL1, has been shown to demethylate di- and mono-methylated H3K4 (Spedaletti et al., 2008). A. thaliana genome also contains 21 JmjC domain-containing proteins (JMJs). These JMJs are grouped into five subfamilies according to sequence similarities. The biochemical properties and biological functions of histone demethylases are emerging and how these enzymes work, are recruited to their target loci, and play roles are still largely unknown (Liu et al., 2010).

In animals, $\mathrm{H} 3$ and $\mathrm{H} 4$ arginines can be desiminate by PADI4 (peptidyl arginine deiminase 4). Deimination could be antagonist of arginine methylation since citrulline prevents arginine from being methylated (Cuthbert et al., 2004). Moreover it could be a way to remove methylation of arginine. In fact, monomethylated arginine could be converted to citrullin by PADI4 (Wang et al., 2004). In addition a family of amine oxidases may be able to demethylate arginine residues using a similar mechanism as they demethylate lysine residues (Bedford and Richard, 2005). In plant, arginine demethylation process is still unknown.

\subsection{Histone methylation in responses to abiotic stresses}

Abiotic stresses modulate expression of different genes. As it has been explained before, gene regulation can be due to chromatin remodeling involving histone modification. In plants, modification of histone methylation occurs during stress responses even if the mode of action and consequence of these changes are still not well understand. These modifications could control stress relative genes. For example, hundreds of stressresponsive genes are targets for $\mathrm{H} 3 \mathrm{~K} 27 \mathrm{me} 3$ in A. thaliana (Zhang et al., 2007).

During a cold stress, methylation of H3K27me3 gradually decreases at the loci of two coldresponsive genes, COR15A and AtGolS3 while expressions of genes increase. Even if Trimethylation of histone $\mathrm{H} 3$ Lys27 (H3K27me3) is generally considered as a negative marker of transcription (Zhang et al., 2007), the link between reduction of H3K27me3 and increase of transcription seems to be not obvious in this case : first COR15A and ATGOLS3 are not 
targets for LHP1 (Zhang et al., 2007), an A. thaliana protein that binds H3K27me3 in vitro (Zhang et al., 2007; Exner et al., 2009) and that has been shown to be required for silencing of genes with H3K27me3 (Mylne et al., 2006; Sung et al., 2006; Zhang et al., 2007; Exner et al., 2009). Also, when cold-exposed plants are returned to normal growth conditions, transcription of COR15A and ATGOLS3 was repressed to the initial level before cold exposure while decrease in $\mathrm{H} 3 \mathrm{~K} 27 \mathrm{me} 3$ is still maintained. Also, this decrease does not enhance the induction of transcription when plants are returned to cold temperatures (Kwon et al., 2009). According to these results, it has been proposed that H3K27me3 could act as a memory marker for recent transcriptional activity in A. thaliana. In this case, previous exposure of plants to certain environmental stresses may negatively affect the level of H3K27me3 and lower the chance of stress-responsive genes being silenced.

Dehydration stress also induces variations on histone methylation. In fact, histone H3 modifications at the coding regions of four dehydration stress responsive genes, RD29A, RD29B, RD20, and an AP2 transcription factor have been reported during a drought stress in A. thaliana (Kim et al., 2008), characterized by an enrichment of H3K4me3 and H3K9ac (a positive marker of gene activation) at these four loci. Another study presents the wholegenome distribution patterns of histone $\mathrm{H} 3 \mathrm{H} 3 \mathrm{~K} 4 \mathrm{me} 1, \mathrm{H} 3 \mathrm{~K} 4 \mathrm{me} 2$, and $\mathrm{H} 3 \mathrm{~K} 4 \mathrm{me} 3$ and its modification after a drought stress in A. thaliana. While H3K4me1 and H3K4me2 levels changed modestly during dehydration stress, drastic changes in the H3K4me3 levels are observed. These changes are correlated with modification in level of transcription of responding genes: a large increase of H3K4me3 level was found on nucleosomes of the genes which had a high expression and a large decrease in H3K4me3 levels has been reported in highly down-regulated genes (van Dijk et al., 2010). By analyzing the H3K4me3 distribution profiles on nucleosomes of stress-induced genes, this study provided specific chromatin pattern associated with many genes involved in dehydration stress response and confirm the putative role of $\mathrm{H} 3 \mathrm{~K} 4 \mathrm{me} 3$ in transcription activation.

The A. thaliana SKB1 protein is a type II Arg methyltransferase homologue to PRMT5 in mammals that catalyzes Arg symmetric dimethylation H4R3sme2. SKB1 is associated to chromatin region of FLC promoting flowering by suppressing its expression through H4R3sme2 (Wang et al., 2007; Schmitz et al., 2008). SKB1 is also associated in chromatin of other genes involving among others in stress responses like HAB1, who is really important in ABA and salt stress (Saez et al., 2004; Saez et al., 2006) where it represses transcription through H4R3sme2. Salt stress and ABA treatment (that is accumulated under a salt stress) lead to dissociation of SKB1 from chromatin leading to a reduced level of H4R3sme2 and to an higher expression of genes in $\mathrm{ABA}$ and salt response like HAB1, suggesting a direct mechanism by which salt and ABA impact gene transcription (Figure 3). This theory is supporting by the fact that SKB1 invalidation leads to a decrease of H4R3sme2 levels, an increase of HAB1 and some other stress-responsive gene expression and a bigger susceptibility to salt stress (Zhang et al., 2011). During a salt stress, SKB1 not only leaves chromatin of some loci but also methylates U6 small nuclear ribonucleoprotein (snRNP)specific Sm-like protein LSM4. SKB1 invalidation leads to splicing defects in hundreds of genes that are involved in many biological processes, including the abiotic stress responses. Furthermore, $l s m 4$ mutant, similarly to $S k b 1$, is hypersensitive to salt and shows similar splicing defects in some genes (Zhang et al., 2011). In conclusion, SKB1 plays a dual role in salt response by altering the methylation status of H4R3sme2 and LSM4. 


\section{A : No stress}

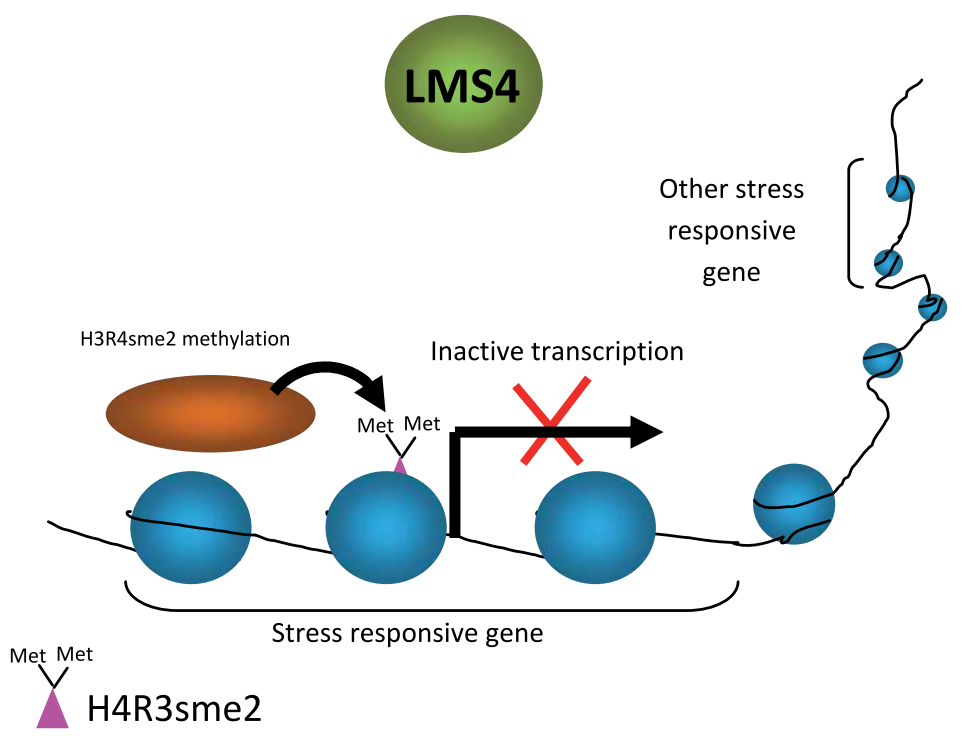

methylation

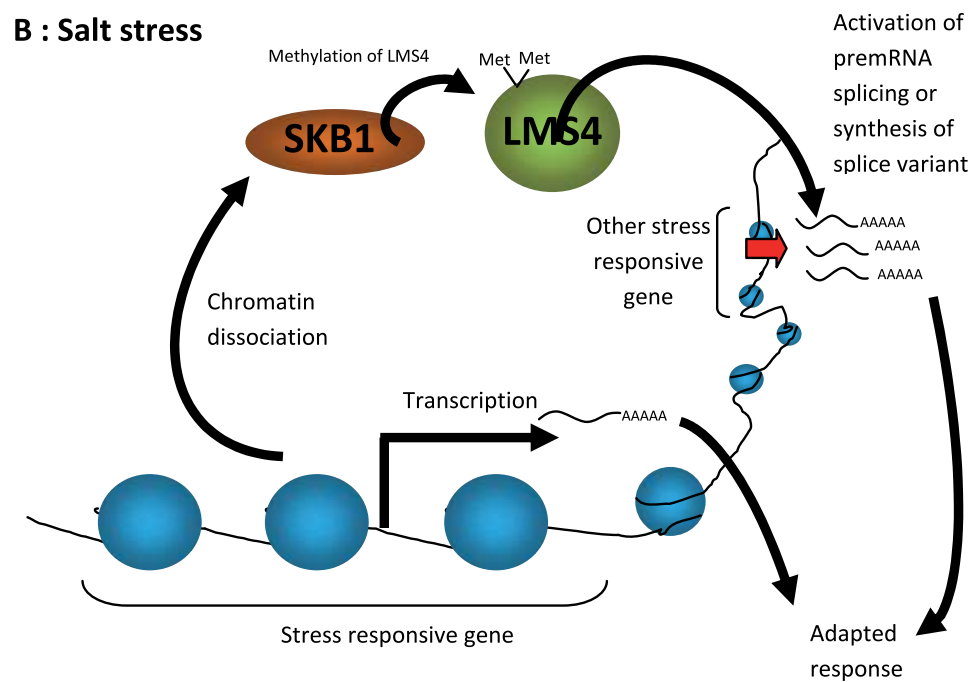

Fig. 3. Involvement of methylation in salt stress responses. A : Without stress, SKB1 a PRMT is associated to the chromatin of some stress related genes where it methylates histone on H4R3sme2. These methylations are repressive mark leading to transcription inactivation of these genes. B: During a salt stress, there is a chromatin dissociation of SKB1. This dissociation has a dual role in stress related gene control to insure an adapted response: Firstly SKB1 do not maintains H3R4sme2 in the loci where it was associated leading to an 
higher expression of many stress relative genes. Secondly, SKB1 will methylated another protein LMS4 connected to splicing. This last methylation leads to an activation of premRNA splicing and / or synthesis of splice variant of some other genes connected to stress responses.

\section{Redox modification of nuclear proteins}

\subsection{ROS and RNS in the nucleus}

Reactive oxygen species (ROS) are chemically reactive species of oxygen formed by successive one-electron reduction of molecular oxygen. It includes superoxide anion $\left(\mathrm{O}_{2} \cdot-{ }^{-}\right)$, hydrogen peroxide $\left(\mathrm{H}_{2} \mathrm{O}_{2}\right)$, perhydroxyl radical $\left(\mathrm{HO}_{2} \cdot\right)$ and the highly reactive hydroxyl radical (OH.) (Apel and Hirt, 2004). ROS is produced in different organelles such as mitochondria, chloroplast, peroxizome, endoplasmic reticulum and in the cytosol (Gill and Tuteja, 2010) but to our knowledge, only one study has described ROS accumulation in the nucleus, in response to an elicitor of plant defense (Ashtamker et al., 2007). However, recent data indicate that plant cell nucleus possesses antioxidant redox system to control ROS homeostasis (Pulido et al., 2009a; Pulido et al., 2009b). Furthermore, ROS production in other cellular compartments results in changes in gene expression, indicating that ROS production can influence gene transcription in the nucleus. Another reactive radical, Nitric Oxide (NO), has been known for years as a signaling molecule in animal and plant cells (Besson-Bard et al., 2008). Reactive Nitrogen Species (RNS) contains all the NO derived molecules and their chemistry have been documented elsewhere (Stamler et al., 1992). For instance, NO can be oxidized or reduced to $\mathrm{NO}^{+}$or $\mathrm{NO}^{-}$or can react with $\mathrm{O}_{2}{ }^{--}$to form the strong oxidant peroxynitrite (ONOO-). Through its different chemical forms, $\mathrm{NO}$ can react with a great variety of molecules including proteins, lipids, metals, molecular oxygen or nucleic acids. Evidences for NO production in the nucleus of various plant cell types (stomata guard cells, stomata subsidiary cells, epidermal cells) have been documented in some studies in response to different stimuli such as heat stress, green light, osmotic stress, plant defense elicitors (Foissner et al., 2000; Gould et al., 2003; Vitecek et al., 2008). As observed for ROS, NO can have an impact on gene expression (Palmieri et al., 2008).

\subsection{Redox-based post-translational modification in plant cell nuclei}

ROS and RNS could affect gene expression through different mechanisms. These reactive compounds can activate components of signaling pathways controlling gene expression or can directly affect the DNA binding activity of several kinds of transcription factors. Heat shock transcription factors (HSF) bind to a consensus sequence found in the promoter of many stress-responsive genes. HSF transcription factors have been thought to be ROS sensors as reviewed by (Miller and Mittler, 2006). Other transcription factors are regulated in a redox dependent manner through a dithiol/disulfide exchange and some examples are detailed bellow.

The activity of transcription factors from the R2R3 MYB family have been shown to be involved in abiotic stress responses including salt stress, drought stress (Jung et al., 2008). Using the typical R2R3 MYB protein P1 from Zea mays, Heine et al. (2004) have shown that DNA binding of this transcription factor is redox-dependent. More precisely, the two cysteines residues 49 and 53 are necessary for DNA binding and under non-reducing conditions, they formed a disulfide bridge that prevents DNA binding. Another R2R3 MYB 
plant transcription factor of $A$. thaliana, AtMYB2, has been shown to be redox-modulated (Serpa et al., 2007). AtMYB2 has been suggested to play a role in response to stresses that induce NO production such as ABA or salt treatment. Contrary to P1, cystein 49 is absent in AtMYB2 (Heine et al., 2004) and the S-nitrosylation of Cys 53 by NO donors blocks its binding to a specific DNA sequence (Serpa et al., 2007). In this case, it indicates that the Snitrosylation of AtMYB2 could be a mechanism to turn off the activity of this protein. However, the role of the redox regulation of R2R3 MYB transcription family protein needs to be addressed in vivo in response to abiotic stresses.

The DNA binding of RAP2.4a (At1g36060), a AP2/DREB-type transcription factors, to the promoter of 2-Cys peroxiredoxin-A gene (2CPA) is redox-regulated by dithiol/disulfide transition of regularoty cysteinyl residues (Wormuth et al., 2007; Shaikhali et al., 2008). Reducing conditions lead to the monomerisation of RAP2.4a whereas oxidizing conditions dimerize or oligomerize RAP2.4a proteins through the formation of disulfide bridges which increased binding affinity of the protein to DNA. Loss-of-function of RAP2.4a affects the adaptation of plants to changes in environmental conditions such as naturally fluctuating light conditions. Furthermore, RAP2.4a transcription factor regulates the expression of genes known to be induced by ROS and involved in abiotic stress tolerance such as ZAT 10 (Mittler et al., 2006). A closed homologue, RAP2.4b (At1g78080) has also been involved in stress response. Mutations in $R A P 2.4 b$ cause altered expression of light and droughtresponsive genes and defects in developmental processes or drought tolerance. However, its redox control as observed with RAP2.4a has not been investigated.

In the last decades, studies in the animal field have indicated that the main mode of action of $\mathrm{NO}$ is based on the post-translational modification of proteins. Firstly, S-nitrosylation consists of the oxidation by $\mathrm{NO}$ of reduced sulfidryl groups of cysteyls residues of proteins thus forming a nitrosothiol (SNO). Secondly, tyrosine nitration is based on the addition of a $\mathrm{NO}_{2}$ group on a tyrosyl residue of a protein. And thirdly, $\mathrm{NO}$ can bind covalently transition metal of metalloproteins. This last process is called metal nitrosation. These NO-based posttranslational modifications of proteins finally affect the activity of the modified proteins. While thousand proteins have been identified in animals to be modified by NO, only a few have been characterized in plants (Astier et al., 2011; Seth and Stamler, 2011). Among them, some are linked with the nucleus function. The best example on the role of NO in the modification of proteins associated with nuclear functions is the transcription coactivator NPR1 (for Non-expressor of Pathogenesis Related-1) in A. thaliana. Although data indicate that NPR1 is important for plant resistance to abiotic stresses (Quilis et al., 2008; Yasuda et al., 2008; Rao et al., 2002), its mode of action and its regulation have been discovered in plants infected by avirulent pathogens or treated by elicitors of plant defense reactions. In untreated cells, NPR1 forms a homo multimeric complex that is sequestered in the cytosol and stabilized by intermolecular disulphide bonds (Mou et al., 2003). In this case, NPR1 monomers still exist. To prevent target gene activation in the absence of inducing stimulus, they are translocated to the nucleus at low rate and finally targeted to the proteasome (Spoel et al., 2010). A role of NO in this process has been recently discovered. It was reported that Snitrosylation of NPR1 by S-nitrosoglutathione (GSNO) at cysteine-156 facilitates its oligomerization and blocks its nuclear translocation (Tada et al., 2008). After the perception of stimuli such as pathogen infection, redox changes dependent on the production of salicylic acid occur. Multimeric NPR1 is reduced to monomers by thioredoxins and NPR1 monomers are then translocated to the nucleus where their interaction with transcription 
factors allowed the regulation of the expression of several genes (Despres et al., 2003; Tada et al., 2008; Fan and Dong, 2002; Boyle et al., 2009). Particularly, NPR1 activates the binding of the b-ZIP transcription factor TGA1 to the activation sequence-1 (as-1) element of the promoter region of defense genes. Disulfide bridge formation involving cysteyl residues 260 and 266 precludes the interaction of TGA1 with NPR1 and then prevents binding of TGA1 to its target DNA element (Despres et al., 2003). Recent mass spectrometry analysis indicated that these cysteyl residues of TGA1 are S-nitrosylated and S-glutathionylated after GSNO treatment (Lindermayr et al., 2010). Furthermore, GSNO enhanced the DNA binding activity of TGA1 to its DNA element in the presence of NPR1. It can be the consequence of conformational changes of both proteins which allow a more effective TGA1-NPR1 interaction and finally a more effective DNA-binding of TGA1. Interestingly, a GSNOinduced nuclear translocation of NPR1 has also been observed by these authors. It could be due to SA-mediated redox-changes since NO induced SA production (Durner et al., 1998; Huang et al., 2004). All these results indicate that NO has a major regulatory role of NPR1 functions by controlling its translocation from the cytosol to the nucleus and by affecting the NPR1/TGA1 complex and downstream dependent responses. Other proteins might be involved in this process. The small oxidoreductases glutaredoxins that mediate redox regulation of proteins through the reduction of disulphide bridges or the glutathionylation of cysteyl residues (Dalle-Donne et al., 2009; Rouhier et al., 2010) has been recently shown to interact with transcription factors from the TGA family in the nucleus of plant cells (Ndamukong et al., 2007; Li et al., 2009). However, the role of GRX in TGA function has not been described yet.

Another protein is redox-modified by NO. In a recent paper, Wawer et al. (2010) have shown that Nicotiana tabacum GAPDH (glyceraldehyde-3-phosphate dehydrogenase) localized in the nucleus and in the cytosol of plant cells. GAPDH was transiently S-nitrosylated after the salt treatment of $N$. tabacum cell suspensions but the role of this NO-dependent modification is not known.

\section{Ubiquitin and ubuquitin-like post-ranslationnal modifications}

Protein post-translational modifications by ubiquitin and ubiquitin-like proteins are essential for a plethora of cell functions in eukaryotic cells and are involved in development processes but also in the responses to biotic and abiotic stresses (Fu et al., 2010; Miura and Hasegawa, 2010; Trujillo and Shirasu, 2010). Ubiquitination is a post-translational modification of proteins corresponding to the reversible attachment of the 76-amino acid protein ubiquitin to target proteins through a well-characterized process (Fu et al., 2010). This three-step enzymatic cascade is catalyzed by ubiquitin-activating enzyme (E1), ubiquitin-conjugating enzyme (E2) and ubiquitin ligase enzyme (E3). A major function of protein ubiquitination is to address proteins to the proteasome for their degradation. However, it can also control intracellular localization of proteins, transcription of DNA and cell cycle. Thus, ubiquitination regulates a great number of cellular processes. There are evidences that the ubiquitination system is involved in regulating signaling pathways controlling plant adaptation to stresses and especially abiotic stresses. Some proteins belonging to the ubiquitination enzymatic machinery and involved in abiotic stress tolerance have been shown to localized in the nucleus of plant cell. AtHOS1, a E3-ubiquitin ligase that control cold tolerance in A. thaliana have been shown to localized in the nucleus after cold stress (Lee et al., 2001, see below). Furthermore, AtDRIP1 and AtDRIP2 (DREB2A- 
interacting protein) are two E3-ubiquitin ligase (Qin et al., 2008). AtDRIP1 is localized in the nucleus of $A$. thaliana cells where it interact with AtDREB2A (Dehydratation-responsive element binding protein 2A), a transcription factor that is important for drought tolerance and controls the expression of water deficit-inducible gene expression. As proposed by (Qin et al., 2008), the ubiquitination of AtDREB2A may occur in a no-stress condition leading to its degradation by the proteasome. However, during drought stress, AtDREB2A is activated by an unknown mechanism. It is possible that the ubiquitination and degradation of AtDREB2A is blocked leading to the accumulation of effective AtDREB2A protein that in turn activate the expression of drought-responsive genes. This result highlights the importance of ubiquitination process in controlling gene transcription in the nucleus.

In addition to ubiquitin, post-translational modification of proteins by ubiquitin-like proteins (Ubls) such as SUMO (small ubiquitin-like modifier), RUB (related to ubiquitin), NEDD8 (neural precursor cell expressed, developmentally down-regulated), ATG8 and ATG12 (autophagy 8 and 12) have been shown to be functional in plants and to control essential cellular processes as observed in other eukaryotes (reviewed by (Miura and Hasegawa, 2010). Among them, modification of proteins by SUMO (SUMOylation) has been one of the most described Ubl-post-translational modifications in plants. SUMO proteins are synthesized as precursors that need to be cleaved by specific proteases to expose a glycyl residue necessary for their ligation to target proteins. The addition of SUMO proteins to a lysyl residue of the target protein is catalyzed in a three-step enzymatic reaction similar to ubiquitinylation (Kurepa et al., 2003).

In A. thaliana, genetic analysis of SUMOylation process indicates that this post-translational modification of proteins is essential for plant development. Thus, mutation in the gene coding AtSCE1 (Arabidopis Sumo-conjugating Enzyme1) or AtSAE2 (Arabidopsis Sumoactivating Enzyme 2) proteins results in embryo lethality (Saracco et al., 2007). The same phenotype was observed in plants in which the genes coding both AtSUMO1 and AtSUMO2 proteins were mutated (Saracco et al., 2007). Number of proteins modified by SUMO have been shown to increase in planta after abiotic stresses including heat, oxidative stress, ethanol, phosphate starvation, salt and cold stress (Kurepa et al., 2003; Miura et al., 2005; Yoo et al., 2006; Miura et al., 2007; Conti et al., 2008; Miller et al., 2010). Furthermore, mutants defective in proteins of the SUMO-conjugating pathway such as AtSIZ1 (arabidopsis SUMO E3 ligase) are impaired in stress responses such as thermotolerance and have been shown to exhibit exaggerated phosphate starvation responses (Miura et al., 2005; Miura et al., 2007) indicating that SUMOylation of proteins is an essential process mediating stress acclimation. As observed in other eukaryotic cells, SUMOylation enzymes (e.g. AtSCEA and SUMO1/2) localized in the nucleus in Arabidopsis (Lois et al., 2003) indicating a role of SUMOylation in controlling many aspects of nuclear function. In rice (Oryza sativa), SUMO-conjugating enzyme (OsSCE1) has been shown to localize in the nucleus. Yeast-two hybrid experiments indicated that OsSCE1 interacts with the heat-inducible pyrophosphatase (PPIase) OsFKBP20, a class of proteins that assist molecular chaperones in reactions associated with protein folding and protein transport across membrane. It was proposed that OsSCE1 and OsFKBP20 proteins mediate in concert the stress response of rice plants (Nigam et al., 2008). In Arabidopsis, heat stress dramatically increased the pool of SUMO conjugates which were mainly detected in the nucleus (Saracco et al., 2007). In a recent proteomic analyses, Miller et al. (2010) have identified 357 SUMOylated proteins in Arabidopsis. Many of them are nuclear proteins that participate in a wide range of processes related to nuclear function, 
such as chromatin modification, DNA maintenance/repair or gene transcription. Furthermore, nuclear SUMOylated proteins identified in non-stressed plants were enriched in oxidative and/or heat-stressed plants. Among the nuclear SUMO conjugates, some transcription factors have been identified (Miura and Hasegawa, 2010). For instance the SUMOylation of AtICE1, a MYC transcription factor involved in cold stress responses in Arabidopsis has been characterized (see below). Protein SUMOylation is a reversible process and de-SUMOylation is catalyzed by SUMO proteases a class of enzymes that is also involved in the generation of mature SUMO proteins. Recently, the Arabidopsis mutants overly tolerant to salt 1 (ots1) and 2 (ots2) has been shown to be mutated in two SUMO proteases OTS1 and OTS2 that act redundantly to regulate salt stress response (Conti et al., 2008). Both proteins are localized in the nucleus indicating that SUMOylation/deSUMOylation of nuclear proteins is likely to control essential processes required for salt stress responses.

It has been shown recently that both ubiquitination and SUMOylation can affect the same protein. During cold stress, Arabidopsis cold responsive genes are induced transiently indicating that their expression is finely regulated. Among the transcription factors that controls cold-gene expression and cold stress tolerance, AtICE1 is a MYC transcription factor that is constitutively expressed. It controls the cold induction of other transcription factors such as AtCBF3 which in turn drive the expression of cold responsive genes. On the contrary, AtMYB15 is a repressor of such genes (Agarwal et al., 2006). ICE1 is post translationnally modified by both ubiquitynation and SUMOylation processes and these processes are thought to provide a fine-tuning for the expression of cold-responsive genes. More precisely, the nuclear-localized SUMO E3 ligase AtSIZ1 (Cheong et al., 2009) mediate the SUMOylation of AtICE1. SUMOylation of AtICE1 is thought to stabilize or activate the protein, leading to the expression of genes required for low temperature tolerance, such as AtCBF3 (Miura et al., 2007). Furthermore, the RING-E3-ubiquitin ligase HOS1 (for high expression of osmotically responsive gene) have been shown to relocalize to the nucleus after a cold treatment (Lee et al., 2001) where it interacts with ICE1. HOS1 mediates the polyubiquitination of ICE1 targeting this transcription factor for degradation by the proteasome (Dong et al., 2006). This leads to the repression of cold responsive genes such as CBF3 by the transcription factor AtMYB15. A model for the opposite role of ubiquitination and SUMOylation in the control of cold-responsive genes during cold episode has been proposed (Miura et al., 2007; Miura and Hasegawa, 2010).

\section{Conclusion}

As we illustrate in this review using studies reporting the involvement of nuclear posttranslational modifications in response to numerous environmental changes, almost all known major abiotic stresses induce one or more nuclear protein modifications to regulate the expression of specific target genes.

After reading this chapter, three main conclusions emerge. Firstly, histone modifications and associated chromatin and gene expression changes appear to be a critical point necessary for establishment of an appropriate biological response. Understanding the regulation of histone modifications, competitions that can occur between different posttranslational modifications (the famous "histone code") and interpretation of these 
modifications by readers proteins is being initiated and should greatly highlight our comprehension of gene expression regulation in response to stresses in the coming years.

Secondly, we should keep in mind that protein modifications do not occur only on histones, but also concern many others proteins such as transcription regulators. However the number of non-histone proteins targeted by the nuclear posttranslational modification machinery remains sparse probably due to the technical difficulties for identification and purification of these very low abundant proteins in the nuclear compartment.

Thirdly, in almost all cases, the chemical and / or physical signals leading to nuclear machinery through the nuclear envelop are still unknown. Here too our knowledge about nuclear pore channels functioning in plant is emerging, but recent discoveries in this field should extend our understanding of how nuclear protein posttranslational modifications are controlled and lead the plant in an appropriate response to stress.

\section{Acknowledgements}

We would like to thank the Conseil Régional de Bourgogne for its financial support. Jennifer Dahan was supported by a grant from the Ministère de l'Enseignement Supérieur et de la Recherche. Agnès Dutartre is supported by a grant from the Université de Bourgogne and the Conseil Régional de Bourgogne, Emmanuel Koen by the Ministère de l'Agriculture et de la Pêche and Olivier Lamotte by the Centre National de la Recherche Scientifique and by the Conseil Régional de Bourgogne (FABER grant n²0109201AAO047S05280).

\section{References}

Agarwal M, Hao Y, Kapoor A, Dong CH, Fujii H, Zheng X and Zhu JK (2006) A R2R3 type MYB transcription factor is involved in the cold regulation of CBF genes and in acquired freezing tolerance. Journal of Biological Chemistry 281: 37636-37645

Ahlfors R, Macioszek V, Rudd J, Brosché M, Schlichting R, Scheel D and Kangasjärvi J (2004) Stress hormone-independent activation and nuclear translocation of mitogenactivated protein kinases in Arabidopsis thaliana during ozone exposure. The Plant Journal 40: 512-522

Aletta JM, Cimato TR and Ettinger MJ (1998) Protein methylation: a signal event in posttranslational modification. Trends in Biochemical Sciences 23: 89-91

Alinsug M, Yu C-W and Wu K (2009) Phylogenetic analysis, subcellular localization, and expression patterns of RPD3/HDA1 family histone deacetylases in plants. BMC Plant Biology 9: 37

Allfrey VG, Faulkner R and A.E. M (1964) Acetylation and methylation of histones and their possible role in the regulation of RNA synthesis. Proceedings of the National Academy of Sciences of the United States of America 51: 786-794

Andreasson E, Jenkins T, Brodersen P, Thorgrimsen S, Petersen NHT, Zhu S, Qiu J-L, Micheelsen P, Rocher A, Petersen M, Newman M-A, Bjorn Nielsen H, Hirt H, Somssich I, Mattsson O and Mundy J (2005) The MAP kinase substrate MKS1 is a regulator of plant defense responses. Embo Journal 24: 2579-2589

Apel K and Hirt H (2004) Reactive oxygen species: metabolism, oxidative stress, and signal transduction. Annual Review of Plant Biology 55: 373 - 379

Aravind L and Koonin EV (1998) Second family of histone deacetylases. Science 280: 1167 
Ashtamker C, Kiss V, Sagi M, Davydov O and Fluhr R (2007) Diverse subcellular locations of cryptogein-induced reactive oxygen species production in tobacco Bright Yellow-2 cells. Plant Physiology 143: 1817-1826

Astier J, Rasul S, Koen E, Manzoor H, Besson-Bard A, Lamotte O, Jeandroz S, Durner J, Lindermayr C and Wendehenne D (2011) S-nitrosylation: An emerging posttranslational protein modification in plants. Plant Science In Press, Corrected Proof

Aufsatz W, Mette MF, van der Winden J, Matzke M and Matzke AJM (2002) HDA6, a putative histone deacetylase needed to enhance DNA methylation induced by double-stranded RNA. Embo Journal 21: 6832-6841

Bannister AJ and Kouzarides T (2005) Reversing histone methylation. Nature 436: 1103-1106

Bedford MT and Clarke SG (2009) Protein arginine methylation in mammals: who, what, and why. Molecular Cell 33: 1-13

Bedford MT and Richard S (2005) Arginine methylation: An emerging regulator of protein function. Molecular Cell 18: 263-272

Belin C, de Franco P-O, Bourbousse C, Chaignepain S, Schmitter J-M, Vavasseur A, Giraudat J, Barbier-Brygoo $\mathrm{H}$ and Thomine S (2006) Identification of features regulating OST1 kinase activity and OST1 function in guard cells. Plant Physiology 141: 13161327

Benhamed M, Martin-Magniette ML, Taconnat L, Bitton F, Servet C, De Clercq R, De Meyer B, Buysschaert C, Rombauts S, Villarroel R, Aubourg S, BeynonnJ, Bhalerao RP, Coupland G, Gruissem W, Menke FLH, Weisshaar B, Renou JP, Zhou DX and Hilson P (2008) Genome-scale Arabidopsis promoter array indetifies targets of the histone acetylreanferase. Plant Journal 56: 493-504

Benhamed M, Bertrand C, Servet C and Zhou DX (2006) Arabidopsis GCN5, HD1, and TAF1/HAF2 interact to regulate histone acetylation required for light-responsive gene expression. Plant Cell 18: 2893 - 2903

Berger SL (2002) Histone modifications in transcriptional regulation. Current Opinion in Genetics \& Development 12: 142-148

Bernatavichute YV, Zhang XY, Cokus S, Pellegrini M and Jacobsen SE (2008) Genome-Wide Association of Histone H3 Lysine Nine Methylation with CHG DNA Methylation in Arabidopsis thaliana. Plos One 3: e3156

Besson-Bard A, Pugin A and Wendehenne D (2008) New insights into nitric oxide signaling in plants. Annual Review of Plant Biology 59: 21-39

Bond DM, Dennis ES, Pogson BJ and Finnegan EJ (2009) Histone acetylation, VERNALIZATION INSENSITIVE 3, FLOWERING LOCUS $C$, and the vernalization response. Molecular Plant 2: 724-737

Boudsocq M, Droillard M-J, Barbier-Brygoo H and Laurière C (2007) Different phosphorylation mechanisms are involved in the activation of sucrose nonfermenting 1 related protein kinases 2 by osmotic stresses and abscisic acid. Plant Molecular Biology 63: 491-503

Bourque S, Dutartre AH, V., Dahan J, Jeandroz S, Pichereaux C, Rossignol M and Wendehenne D (2011) Type-2 histone deacetylases as new regulators of elicitor-1 induced cell death in plants. New Phytol.: In press

Boyle P, Le Su E, Rochon A, Shearer HL, Murmu J, Chu JY, Fobert PR and Despres C (2009) The BTB/POZ domain of the Arabidopsis disease resistance protein NPR1 interacts with the repression domain of TGA2 to negate its function. Plant Cell 21: 3700-3713 
Burza AM, Pekala I, Sikora J, Siedlecki P, Malagocki P, Bucholc M, Koper L, Zielenkiewicz P, Dadlez M and Dobrowolska G (2006) Nicotiana tabacum osmotic stress-activated kinase is regulated by phosphorylation on Ser-154 and Ser-158 in the kinase activation loop. Journal of Biological Chemistry 281: 34299-34311

Champion A, Kreis M, Mockaitis K, Picaud A and Henry Y (2004) Arabidopsis kinome: after the casting. Functional \& Integrative Genomics 4: 163-187

Chehab EW, Patharkar OR, Hegeman AD, Taybi T and Cushman JC (2004) Autophosphorylation and subcellular localization dynamics of a salt- and water deficit-induced Calcium-Dependent Protein Kinase from ice plant. Plant Physiology 135: 1430-1446

Chen L-T, Luo M, Wang Y-Y and Wu K (2010) Involvement of Arabidopsis histone deacetylase HDA6 in ABA and salt stress response. Journal of Experimental Botany 61: 3345-3353

Chen L-T and Wu K (2010) Role of histone deacetylases HDA6 and HDA19 in ABA and abiotic stress response. Plant Signaling Behaviour 5: 1318-1320

Chen ZJ and Tian L (2007) Roles of dynamic and reversible histone acetylation in plant development and polyploidy. Biochimica et Biophysica Acta (BBA) - Gene Structure and Expression 1769: 295-307

Cheong MS, Park HC, Hong MJ, Lee J, Choi W, Jin JB, Bohnert HJ, Lee SY, Bressan RA and Yun DJ (2009) Specific domain structures control abscisic acid-, salicylic acid-, and stress-mediated SIZ1 phenotypes. Plant Physiology 151: 1930-1942

Choi H-i, Park H-J, Park JH, Kim S, Im M-Y, Seo H-H, Kim Y-W, Hwang I and Kim SY (2005) Arabidopsis Calcium-Dependent Protein Kinase AtCPK32 interacts with $\mathrm{ABF} 4$, a transcriptional regulator of abscisic acid-responsive gene expression, and modulates its activity. Plant Physiology 139: 1750-1761

Clarke S (1993) Protein methylation. Current Opinion in Cell Biology 5: 977-983

Cohen P (2000) The regulation of protein function by multisite phosphorylation - a 25 year update. Trends in Biochemical Sciences 25: 596-601

Conti L, Price G, O'Donnell E, Schwessinger B, Dominy P and Sadanandom A (2008) Small ubiquitin-like modifier proteases OVERLY TOLERANT TO SALT1 and -2 regulate salt stress responses in Arabidopsis. Plant Cell 20: 2894-2908

Cuthbert GL, Daujat S, Snowden AW, Erdjument-Bromage H, Hagiwara T, Yamada M, Schneider R, Gregory PD, Tempst P, Bannister AJ and Kouzarides T (2004) Histone deimination antagonizes arginine methylation. Cell 118: 545-553

Dahan J, Pichereaux C, Rossignol M, Blanc S, Wendehenne D, Pugin A and Bourque S (2009) Activation of a nuclear-localized SIPK in tobacco cells challenged by cryptogein, an elicitor of plant defence reactions. Biochemical Journal 418: 191-200

Dahan J, Wendehenne D, Ranjeva R, Pugin A and Bourque S (2010) Plant protein kinases: still enigmatic components in plant cell signalling. New Phytologist 185: 355-368

Dalle-Donne I, Rossi R, Colombo G, Giustarini D and Milzani A (2009) Protein Sglutathionylation: a regulatory device from bacteria to humans. Trends in Biochemical Sciences 34: 85-96

Dammann C, Ichida A, Hong B, Romanowsky SM, Hrabak EM, Harmon AC, Pickard BG and Harper JF (2003) Subcellular targeting of nine Calcium-Dependent Protein Kinase isoforms from Arabidopsis. Plant Physiology 132: 1840-1848 
Dangl M, Brosch G, Haas H, Loidl P and Lusser A (2001) Comparative analysis of HD2 type histone deacetylases in higher plants. Planta 213: 280-285

Demetriou K, Kapazoglou A, Bladenopoulos K and Tsaftaris A (2009) Epigenetic chromatin modifiers in barley: II. Characterization and expression analysis of the HDA1 family of barley histone deacetylases during development and in response to jasmonic acid. Plant Molecular Biology Reporter 28: 9-21

Despres C, Chubak C, Rochon A, Clark R, Bethune T, Desveaux D and Fobert PR (2003) The Arabidopsis NPR1 disease resistance protein is a novel cofactor that confers redox regulation of DNA binding activity to the basic domain/leucine zipper transcription factor TGA1. Plant Cell 15: 2181-2191

Dong CH, Agarwal M, Zhang Y, Xie Q and Zhu JK (2006) The negative regulator of plant cold responses, HOS1, is a RING E3 ligase that mediates the ubiquitination and degradation of ICE1. Proceeding of the National Academy of Science of the United States of America 103: 8281-8286

Droillard M-J, Boudsocq M, Barbier-Brygoo H and Laurière C (2002) Different protein kinase families are activated by osmotic stresses in Arabidopsis thaliana cell suspensions: Involvement of the MAP kinases AtMPK3 and AtMPK6. FEBS Letters 527: 43-50

Droillard M-J, Boudsocq M, Barbier-Brygoo H and Laurière C (2004) Involvement of MPK4 in osmotic stress response pathways in cell suspensions and plantlets of Arabidopsis thaliana: activation by hypoosmolarity and negative role in hyperosmolarity tolerance. FEBS Letters 574: 42-48

Dubos C, Stracke R, Grotewold E, Weisshaar B, Martin C and Lepiniec L (2010) MYB transcription factors in Arabidopsis. Trends in Plant Science 15: 573-581

Durner J, Wendehenne D and Klessig DF (1998) Defense gene induction in tobacco by nitric oxide, cyclic GMP, and cyclic ADP-ribose. Proceedings of the National Academy of Sciences of the United States of America 95: 10328-10333

Earley K, Lawrence RJ, Pontes O, Reuther R, Enciso AJ, Silva M, Neves N, Gross M, Viegas W and Pikaard CS (2006) Erasure of histone acetylation by Arabidopsis HDA6 mediates large-scale gene silencing in nucleolar dominance. Genes \& Development 20: 1283-1293

Exner V, Aichinger E, Shu H, Wildhaber T, Alfarano P, Caflisch A, Gruissem W, Kohler C and Hennig L (2009) The chromodomain of LIKE HETEROCHROMATIN PROTEIN 1 is essential for H3K27me3 binding and function during Arabidopsis development. Plos One 4: e5335

Fan W and Dong X (2002) In vivo interaction between NPR1 and transcription factor TGA2 leads to salicylic acid-mediated gene activation in Arabidopsis. Plant Cell 14: 13771389

Feng Q, Wang HB, Ng HH, Erdjument-Bromage H, Tempst P, Struhl K and Zhang Y (2002) Methylation of H3-lysine 79 is mediated by a new family of HMTases without a SET domain. Current Biology 12: 1052-1058

Finnin MS, Donigian JR, Cohen A, Richon VM, Rifkind RA, Marks PA, Breslow R and Pavletich NP (1999) Structures of a histone deacetylase homologue bound to the TSA and SAHA inhibitors. Nature 401: 188-193

Foissner I, Wendehenne D, Langebartels C and Durner J (2000) In vivo imaging of an elicitorinduced nitric oxide burst in tobacco. Plant Journal 23: 817-824 
Fong PM, Tian L and Chen ZJ (2006) Arabidopsis thaliana histone deacetylase 1 (AtHD1) is localized in euchromatic regions and demonstrates histone deacetylase activity in vitro. Cell Research 16: 479-488

Fu H, Lin YL and Fatimababy AS (2010) Proteasomal recognition of ubiquitylated substrates. Trends in Plant Science 15: 375-386

$\mathrm{Fu} \mathrm{W,} \mathrm{Wu} \mathrm{K} \mathrm{and} \mathrm{Duan} \mathrm{J} \mathrm{(2007)} \mathrm{Sequence} \mathrm{and} \mathrm{expression} \mathrm{analysis} \mathrm{of} \mathrm{histone} \mathrm{deacetylases} \mathrm{in}$ rice. Biochemical and Biophysical Research Communications 356: 843-850

Fuchs J, Demidov D, Houben A and Schubert I (2006) Chromosomal histone modification patterns - from conservation to diversity. Trends in Plant Science 11: 199-208

Fujii H, Chinnusamy V, Rodrigues A, Rubio S, Antoni R, Park S-Y, Cutler SR, Sheen J, Rodriguez PL and Zhu J-K (2009) In vitro reconstitution of an abscisic acid signalling pathway. Nature 462: 660-664

Fujita Y, Nakashima K, Yoshida T, Katagiri T, Kidokoro S, Kanamori N, Umezawa T, Fujita M, Maruyama K, Ishiyama K, Kobayashi M, Nakasone S, Yamada K, Ito T, Shinozaki K and Yamaguchi-Shinozaki K (2009) Three SnRK2 protein kinases are the main positive regulators of abscisic acid signaling in response to water stress in Arabidopsis. Plant and Cell Physiology 50: 2123-2132

Gallwitz D (1971) Orgab specificity of histone acetyltranferases. FEBS Letters 13: 306-308

Gao M-J, Hegedus D, Sharpe A, Robinson S, Lydiate D and Hannoufa A (2007) Isolation and characterization of a GCN5-interacting protein from Arabidopsis thaliana. Planta 225: 1367-1379

Gao M-J, Schäfer UA, Parkin IAP, Hegedus DD, Lydiate DJ and Hannoufa A (2003) A novel protein from Brassica napus has a putative KID domain and responds to low temperature. Plant Journal 33: 1073-1086

Gao M, Liu J, Bi D, Zhang Z, Cheng F, Chen S and Zhang Y (2008) MEKK1, MKK1/MKK2 and MPK4 function together in a mitogen-activated protein kinase cascade to regulate innate immunity in plants. Cell Research 18: 1190-1198

Gardner KE, Zhou L, Parra MA, Chen X and Strahl BD (2011) Identification of Lysine 37 of Histone H2B as a Novel Site of Methylation. Plos One 13: e16244

Gary JD and Clarke S (1998) RNA and protein interactions modulated by protein arginine methylation. Progress in Nucleic Acid Research and Molecular Biology, Vol 6161 : 65-131

Gill SS and Tuteja N (2010) Reactive oxygen species and antioxidant machinery in abiotic stress tolerance in crop plants. Plant Physiology and Biochemistry 48: 909-930

Gonzalez D, Bowen AJ, Carroll TS and Conlan RS (2007) The transcription corepressor LEUNIG interacts with the histone deacetylase HDA19 and mediator components MED14 (SWP) and CDK8 (HEN3) to repress transcription. Molecular and Cell Biology 27: 5306-5315

Gould K, Lamotte O, Klinguer A, Pugin A and Wendehenne D (2003) Nitric oxide production in tobacco leaf cells: a generalized stress response? Plant Cell Environment 16: 1851-1862

Guo L, Yin BL, Zhou JL, Li XY and Deng XW (2006) Development of rabbit monoclonal and polyclonal antibodies for detection of site-specific histone modifications and their application in analyzing overall modification levels. Cell Research 16: 519-527 
Halford NG and Hey SJ (2009) Snf1-related protein kinases (SnRKs) act within an intricate network that links metabolic and stress signalling in plants. Biochemical Journal 419: 247-259

Hanks SK and Hunter T (1995) Protein kinases 6. The eukaryotic protein kinase superfamily: kinase (catalytic) domain structure and classification. The FASEB Journal 9: 576-596

Hark AT, Vlachonasios KE, Pavangadkar KA, Rao S, Gordon H, Adamakis I-D, Kaldis A, Thomashow MF and Triezenberg SJ (2009) Two Arabidopsis orthologs of the transcriptional coactivator ADA2 have distinct biological functions. Biochimica et Biophysica Acta (BBA) - Gene Regulatory Mechanisms 1789: 117-124

Harmon AC (2003) Calcium-regulated protein kinases of plants. Gravitatiobal and Space Biology Bulletin 16: 83-90

Hayes JJ and Hansen JC (2001) Nucleosomes and the chromatin fiber. Current Opinion in Genetics \& Development 11: 124-129

Heine GF, Hernandez JM and Grotewold E (2004) Two cysteines in plant R2R3 MYB domains participate in REDOX-dependent DNA binding. Journal of Biological Chemistry 279: 37878-37885

Huang X, Stettmaier K, Michel C, Hutzler P, Mueller M and Durner J (2004) Nitric oxide is induced by wounding and influences jasmonic acid signaling in Arabidopsis thaliana. Planta 218: 938-946

Hubbard KE, Nishimura N, Hitomi K, Getzoff ED and Schroeder JI (2010) Early abscisic acid signal transduction mechanisms: newly discovered components and newly emerging questions. Genes \& Development 24: 1695-1708

Ichimura K, Mizoguchi T, Yoshida R, Yuasa T and Shinozaki K (2000) Various abiotic stresses rapidly activate Arabidopsis MAP kinases ATMPK4 and ATMPK6. Plant Journal 24: 655-665

Imai S, Armstrong CM, Kaeberlein M and Guarente L (2000) Transcriptional silencing and longevity protein Sir2 is an NAD-dependent histone deacetylase. Nature: 795-800

Inoue A and Fujimoto D (1969) Enzymatic deacetylation of histone. Biochemical and Biophysical Research Communications 36: 146-150

Jackson JP, Johnson L, Jasencakova Z, Zhang X, PerezBurgos L, Singh PB, Cheng XD, Schubert I, Jenuwein T and Jacobsen SE (2004) Dimethylation of histone H3 lysine 9 is a critical mark for DNA methylation and gene silencing in Arabidopsis thaliana. Chromosoma 112: 308-315

Jenuwein T and Allis CD (2001) Translating the histone code. Science 293: 1074-1080

Jenuwein T, Laible G, Dorn R and Reuter G (1998) SET domain proteins modulate chromatin domains in eu- and heterochromatin. Cellular and Molecular Life Sciences 54: 80-93

Johnson L, Mollah S, Garcia BA, Muratore TL, Shabanowitz J, Hunt DF and Jacobsen SE (2004) Mass spectrometry analysis of Arabidopsis histone H3 reveals distinct combinations of post-translational modifications. Nucleic Acids Research 32: 65116518

Johnson LM, Cao XF and Jacobsen SE (2002) Interplay between two epigenetic marks: DNA methylation and histone H3 lysine 9 methylation. Current Biology 12: 1360-1367

Jones AME, MacLean D, Studholme DJ, Serna-Sanz A, Andreasson E, Rathjen JP and Peck SC (2009) Phosphoproteomic analysis of nuclei-enriched fractions from Arabidopsis thatiana. Journal of Proteomics 72: 439-451 
Jung C, Seo JS, Han SW, Koo YJ, Kim CH, Song SI, Nahm BH, Choi YD and Cheong J-J (2008) Overexpression of AtMYB44 enhances stomatal closure to confer abiotic stress tolerance in transgenic Arabidopsis. Plant Physiology 146: 623-635

Kaldis A, Tsementzi D, Tanriverdi O and Vlachonasios K (2011) Arabidopsis thaliana transcriptional co-activators $\mathrm{ADA} 2 \mathrm{~b}$ and SGF29a are implicated in salt stress responses. Planta 233: 749-762

Kerk D, Bulgrien J, Smith DW, Barsam B, Veretnik S and Gribskov M (2002) The complement of protein phosphatase catalytic subunits encoded in the genome of Arabidopsis. Plant Physiology 129: 908-925

Kim JM, To TK, Ishida J, Morosawa T, Kawashima M, Matsui A, Toyoda T, Kimura H, Shinozaki K and Seki M (2008) Alterations of lysine modifications on the histone H3 N-Tail under drought stress conditions in Arabidopsis thaliana. Plant and Cell Physiology 49: 1580-1588

Klimecka M and Muszynska G (2007) Structure and functions of plant calcium-dependent protein kinases. Acta Biochimica Polonica 54: 219-233

Klose RJ and Yi Z (2007) Regulation of histone methylation by demethylimination and demethylation. Nature Reviews Molecular Cell Biology 8: 307-318

Kobayashi Y, Murata M, Minami H, Yamamoto S, Kagaya Y, Hobo T, Yamamoto A and Hattori T (2005) Abscisic acid-activated SNRK2 protein kinases function in the gene-regulation pathway of ABA signal transduction by phosphorylating ABA response element-binding factors. Plant Journal 44: 939-949

Kornberg RD and Lorch YL (1999) Twenty-five years of the nucleosome, fundamental particle of the eukaryote chromosome. Cell 98: 285-294

Kosetsu K, Matsunaga S, Nakagami H, Colcombet J, Sasabe M, Soyano T, Takahashi Y, Hirt $\mathrm{H}$ and Machida Y (2010) The MAP kinase MPK4 is required for cytokinesis in Arabidopsis thaliana. Plant Cell 22: 3778-3790

Kouzarides T (2002) Histone methylation in transcriptional control. Current Opinion in Genetics \& Development 12: 198-209

Kouzarides T (2007) Chromatin modifications and their function. Cell 128: 693 - 705

Kudla J, Batistic O and Hashimoto K (2010) Calcium signals: the lead currency of plant information processing. Plant Cell 22: 541-563

Kurepa J, Walker JM, Smalle J, Gosink MM, Davis SJ, Durham TL, Sung DY and Vierstra RD (2003) The small ubiquitin-like modifier (SUMO) protein modification system in Arabidopsis. Accumulation of SUMO1 and -2 conjugates is increased by stress. Journal of Biological Chemistry 278: 6862-6872

Kwon CS, Lee D, Choi G and Chung WI (2009) Histone occupancy-dependent and independent removal of H3K27 trimethylation at cold-responsive genes in Arabidopsis. Plant Journal 60: 112-121

Lechner T, Lusser A, Pipal A, Brosch G, Loidl A, Goralik-Schramel M, Sendra R, Wegener S, Walton JD and Loidl P (2000) RPD3-type histone deacetylases in maize embryos. Biochemistry 39: 1683-1692

Lee DY, Teyssier C, Strahl BD and Stallcup MR (2005) Role of protein methylation in regulation of transcription. Endocrine Reviews 26: 147-170

Lee H, Xiong L, Gong Z, Ishitani M, Stevenson B and Zhu JK (2001) The Arabidopsis HOS1 gene negatively regulates cold signal transduction and encodes a RING finger 
protein that displays cold-regulated nucleo--cytoplasmic partitioning. Genes and Development 15: 912-924

Li J (2005) Brassinosteroid signaling: from receptor kinases to transcription factors. Current Opinion in Plant Biology 8: 526-531

Li S, Lauri A, Ziemann M, Busch A, Bhave M and Zachgo S (2009) Nuclear activity of ROXY1, a glutaredoxin interacting with TGA factors, is required for petal development in Arabidopsis thaliana. Plant Cell 21: 429-441

Lin C-H, Li B, Swanson S, Zhang Y, Florens L, Washburn MP, Abmayr SM and Workman JL (2008) Heterochromatin protein 1a stimulates histone H3 lysine 36 demethylation by the Drosophila KDM4A demethylase. Molecular cell 32: 696-706

Lindermayr C, Sell S, Müller B, Leister D and Durner J (2010) Redox regulation of the NPR1TGA1 system of Arabidopsis thaliana by nitric oxide. Plant Cell 22: 2894-2907

Lippman Z, Gendrel AV, Black M, Vaughn MW, Dedhia N, McCombie WR, Lavine K, Mittal V, May B, Kasschau KD, Carrington JC, Doerge RW, Colot V and Martienssen R (2004) Role of transposable elements in heterochromatin and epigenetic control. Nature 430: 471-476

Lippman Z, May B, Yordan C, Singer T and Martienssen R (2003) Distinct mechanisms determine transposon inheritance and methylation via small interfering RNA and mistone modification. PLoS Biol 1: e67

Liu CY, Lu FL, Cui X and Cao XF (2010) Histone Methylation in Higher Plants. Annual Review of Plant Biology, 61: 395-420

Lois LM, Lima CD and Chua NH (2003) Small ubiquitin-like modifier modulates abscisic acid signaling in Arabidopsis. Plant Cell 15: 1347-1359

Lu FL, Li GL, Cui X, Liu CY, Wang XJ and Cao XF (2008) Comparative analysis of JmjC domain-containing proteins reveals the potential histone demethylases in Arabidopsis and rice. Journal of Integrative Plant Biology 50: 886-896

Luan S (2003) Protein phosphatases in plants. Annual Review of Plant Biology 54: 63-92

Luscombe NM, Laskowski RA and Thornton JM (2001) Amino acid-base interactions: a three-dimensional analysis of protein-DNA interactions at an atomic level. Nucleic Acids Research 29: 2860-2874

Lusser A, Brosch G, loidl A, Haas H and Loidl P (1997) Identification of histone deacetylase HD2 as an acidic nucleolar phosphoprotein. Science 277: 88-91

Mao Y, Pavangadkar KA, Thomashow MF and Triezenberg SJ (2006) Physical and functional interactions of Arabidopsis ADA2 transcriptional coactivator proteins with the acetyltransferase GCN5 and with the cold-induced transcription factor CBF1. Biochimica et Biophysica Acta (BBA) - Gene Structure and Expression 1759: 69-79

Mathieu O, Probst AV and Paszkowski J (2005) Distinct regulation of histone H3 methylation at lysines 27 and 9 by CpG methylation in Arabidopsis. Embo Journal 24: 2783-2791

May BP, Lippman ZB, Fang Y, Spector DL and Martienssen RA (2005) Differential regulation of strand-specific transcripts from Arabidopsis centromeric satellite repeats. PLoS Genet 1: e79

Mazars C, Bourque S, Mithöfer A, Pugin A and Ranjeva R (2009) Calcium homeostasis in plant cell nuclei. New Phytologist 181: 261-274 
Mehlmer N, Wurzinger B, Stael S, Hofmann-Rodrigues D, Csaszar E, Pfister B, Bayer R and Teige $\mathrm{M}$ (2010) The $\mathrm{Ca}^{2+-}$ dependent protein kinase CPK3 is required for MAPKindependent salt-stress acclimation in Arabidopsis. Plant Journal 63: 484-498

Menke FLH, Kang H-G, Chen Z, Park JM, Kumar D and Klessig DF (2005) Tobacco transcription factor WRKY1 is phosphorylated by the MAP kinase SIPK and mediates HR-like cell death in tobacco. Molecular Plant-Microbe Interactions 18: 1027-1034

Mikolajczyk M, Awotunde OS, Muszynska G, Klessig DF and Dobrowolska G (2000) Osmotic stress induces rapid activation of a salicylic acid-induced protein kinase and a homolog of protein kinase ASK1 in tobacco cells. Plant Cell 12: 165-178

Miller GAD and Mittler RON (2006) Could heat shock transcription factors function as hydrogen peroxide sensors in plants? Annals of Botany 98: 279-288

Miller MJ, Barrett-Wilt GA, Hua Z and Vierstra RD (2010) Proteomic analyses identify a diverse array of nuclear processes affected by small ubiquitin-like modifier conjugation in Arabidopsis. Proceeding of the National Academy of Science of the United States of America 107: 16512-16517

Miranda-Saavedra D and Barton GJ (2007) Classification and functional annotation of eukaryotic protein kinases. Proteins: Structure, Function, and Bioinformatics 68: 893-914

Mitchell JBO, Thornton JM, Singh J and Price SL (1992) Towards an understanding of the arginine aspartate interaction. Journal of Molecular Biology 226: 251-262

Mittler R, Kim Y, Song LH, Coutu J, Coutu A, Ciftci-Yilmaz S, Lee H, Stevenson B and Zhu JK (2006) Gain- and loss-of-function mutations in Zat10 enhance the tolerance of plants to abiotic stress. Febs Letters 580: 6537 - 6542

Miura K and Hasegawa PM (2010) Sumoylation and other ubiquitin-like post-translational modifications in plants. Trends in Cellular Biology 20: 223-232

Miura K, Jin JB, Lee J, Yoo CY, Stirm V, Miura T, Ashworth EN, Bressan RA, Yun DJ and Hasegawa PM (2007) SIZ1-mediated sumoylation of ICE1 controls CBF3/DREB1A expression and freezing tolerance in Arabidopsis. Plant Cell 19: 1403-1414

Miura K, Rus A, Sharkhuu A, Yokoi S, Karthikeyan AS, Raghothama KG, Baek D, Koo YD, Jin JB, Bressan RA, Yun DJ and Hasegawa PM (2005) The Arabidopsis SUMO E3 ligase SIZ1 controls phosphate deficiency responses. Proceeding of the National Academy of Science of the United States of America 102: 7760-7765

Moorhead GBG, De wever V, Templeton G and Kerk D (2009) Evolution of protein phosphatases in plants and animals. Biochemical Journal 417: 401-409

Mou Z, Fan W and Dong X (2003) Inducers of plant systemic acquired resistance regulate NPR1 function through redox changes. Cell 113: 935-944

Murfett J, Wang X-J, Hagen G and Guilfoyle TJ (2001) Identification of Arabidopsis histone deacetylase hda6 mutants that affect transgene expression. Plant Cell 13: 1047-1062

Mylne JS, Barrett L, Tessadori F, Mesnage S, Johnson L, Bernatavichute YV, Jacobsen SE, Fransz P and Dean C (2006) LHP1, the Arabidopsis homologue of HETEROCHROMATIN PROTEIN1, is required for epigenetic silencing of FLC. Proceedings of the National Academy of Sciences of the United States of America 103: 5012-5017 
Ndamukong I, Abdallat AA, Thurow C, Fode B, Zander M, Weigel R and Gatz C (2007) SAinducible Arabidopsis glutaredoxin interacts with TGA factors and suppresses JAresponsive PDF1.2 transcription. Plant Journal 50: 128-139

Nigam N, Singh A, Sahi C, Chandramouli A and Grover A (2008) SUMO-conjugating enzyme (Sce) and FK506-binding protein (FKBP) encoding rice (Oryza sativa L.) genes: genome-wide analysis, expression studies and evidence for their involvement in abiotic stress response. Molecular Genetics and Genomics 279: 371383

Niu LF, Lu FL, Pei YX, Liu CY and Cao XF (2007) Regulation of flowering time by the protein arginine methyltransferase AtPRMT10. EMBO Reports 8: 1190-1195

Owen DJ, Ornaghi P, Yang J-C, Lowe N, Evans PR, Ballario P, Neuhaus D, Filetici P and Travers AA (2000) The structural basis for the recognition of acetylated histone H4 by the bromodomain of histone acetyltransferase Gcn5p. EMBO Journal 19: 61416149

Palmieri MC, Sell S, Huang X, Scherf M, Werner T, Durner J and Lindermayr C (2008) Nitric oxide-responsive genes and promoters in Arabidopsis thaliana: a bioinformatics approach. Journal of Experimental Botany 59: 177-186

Pandey R, Müller A, Napoli CA, Selinger DA, Pikaard CS, Richards EJ, Bender J, Mount DW and Jorgensen RA (2002) Analysis of histone acetyltransferase and histone deacetylase families of Arabidopsis thaliana suggests functional diversification of chromatin modification among multicellular eukaryotes. Nucleic Acids Research 30: 5036-5055

Pei YX, Niu LF, Lu FL, Liu CY, Zhai JX, Kong XF and Cao XF (2007) Mutations in the type II protein arginine methyltransferase AtPRMT5 result in pleiotropic developmental defects in Arabidopsis(1[C][OA]). Plant Physiology 144: 1913-1923

Pipal A, Goralik-Schramel M, Lusser A, Lanzanova C, Sarg B, Loidl A, Lindner H, Rossi V and Loidl P (2003) Regulation and processing of maize histone deacetylase Hda1 by limited proteolysis. Plant Cell 15: 1904-1917

Probst AV, Fagard M, Proux F, Mourrain P, Boutet S, Earley K, Lawrence RJ, Pikaard CS, Murfett J, Furner I, Vaucheret H and Scheid OM (2004) Arabidopsis distone deacetylase HDA6 is required for maintenance of transcriptional gene silencing and determines nuclear organization of rDNA repeats. Plant Cell 16: 1021-1034

Pulido P, Cazalis R and Cejudo FJ (2009a) An antioxidant redox system in the nucleus of wheat seed cells suffering oxidative stress. Plant Journal 57: 132-145

Pulido P, Dominquez F and Cejudo FJ (2009b) A hydrogen peroxide detoxification system in the nucleus of wheat seed cells: protection or signaling role? Plant Signaling Behavior 4: 23-25

Qin F, Sakuma Y, Tran LS, Maruyama K, Kidokoro S, Fujita Y, Fujita M, Umezawa T, Sawano Y, Miyazono K, Tanokura M, Shinozaki K and Yamaguchi-Shinozaki K (2008) Arabidopsis DREB2A-interacting proteins function as RING E3 ligases and negatively regulate plant drought stress-responsive gene expression. Plant Cell 20: 1693-1707

Qiu J-L, Fiil BK, Petersen K, Nielsen HB, Botanga CJ, Thorgrimsen S, Palma K, SuarezRodriguez MC, Sandbech-Clausen S, Lichota J, Brodersen P, Grasser KD, Mattsson O, Glazebrook J, Mundy J and Petersen M (2008) Arabidopsis MAP kinase 4 
regulates gene expression through transcription factor release in the nucleus. EMBO Journal 27: 2214-2221

Quilis J, Penas G, Messeguer J, Brugidou C and Segundo BS (2008) The Arabidopsis AtNPR1 inversely modulates defense responses against fungal, bacterial, or viral pathogens while conferring hypersensitivity to abiotic stresses in transgenic rice. Molecular Plant-Microbe Interactions 21: 1215-1231

Rao MV, Lee H-i and Davis KR (2002) Ozone-induced ethylene production is dependent on salicylic acid, and both salicylic acid and ethylene act in concert to regulate ozoneinduced cell death. Plant Journal 32: 447-456

Rossi V, Hartings H and Motto M (1998) Identification and caracterisation of an RDP3 homologue from maize (Zea mays L.) that is able to complement an rpd3 null mutant of Saccharomyces cerevisiaeI. Molecular and General Genetics 258: 288-296

Rouhier N, Couturier J, Johnson MK and Jacquot J-P (2010) Glutaredoxins: roles in iron homeostasis. Trends in Biochemical Sciences 35: 43-52

Rundlett SE, Carmen AA, Kobayashi R, Bavykin S, Turner BM and Grunstein M (1996) HDA1 and RPD3 are members of distinct yeast histone deacetylase complexes that regulate silencing andâ€\%otranscription. Proceedings of the National Academy of Sciences of the United States of America 93: 14503-14508

Rushton PJ, Somssich IE, Ringler P and Shen QJ (2010) WRKY transcription factors. Trends in Plant Science 15: 247-258

Saez A, Apostolova N, Gonzalez-Guzman M, Gonzalez-Garcia MP, Nicolas C, Lorenzo O and Rodriguez PL (2004) Gain-of-function and loss-of-function phenotypes of the protein phosphatase 2C HAB1 reveal its role as a negative regulator of abscisic acid signalling. Plant Journal 37: 354-369

Saez A, Robert N, Maktabi MH, Schroeder JI, Serrano R and Rodriguez PL (2006) Enhancement of abscisic acid sensitivity and reduction of water consumption in Arabidopsis by combined inactivation of the protein phosphatases type 2C ABI and HAB1. Plant Physiology 141: 1389-1399

Samuel MA and Ellis BE (2002) Double jeopardy: both overexpression and suppression of a redox-activated plant mitogen-activated protein kinase render tobacco plants ozone sensitive. Plant Cell 14: 2059-2069

Saracco SA, Miller MJ, Kurepa J and Vierstra RD (2007) Genetic analysis of SUMOylation in Arabidopsis: conjugation of SUMO1 and SUMO2 to nuclear proteins is essential. Plant Physiology 145: 119-134

Schmitz RJ, Sung S and Amasino RM (2008) Histone arginine methylation is required for vernalization-induced epigenetic silencing of FLC in winter-annual Arabidopsis thaliana. Proceedings of the National Academy of Sciences of the United States of America 105: 411-416

Schotta G, Ebert A, Krauss V, Fischer A, Hoffmann J, Rea S, Jenuwein T, Dorn R and Reuter G (2002) Central role of Drosophila SU(VAR)3-9 in histone H3-K9 methylation and heterochromatic gene silencing. EMBO Journal 21: 1121-1131

Serpa V, Vernal J, Lamattina L, Grotewold E, Cassia R and Terenzi H (2007) Inhibition of AtMYB2 DNA-binding by nitric oxide involves cysteine S-nitrosylation. Biochemical and Biophysical Research Communications 361: 1048-1053 
Servet C, Conde E, Silva N and Zhou DX (2010) Histone acetyltransferase AtGCN5/HAG1 is a versatile regulator of developmentat and inducible gene expression in Arabidopsis. Molecular Plant 3: 670-677

Seth D and Stamler JS (2011) The SNO-proteome: causation and classifications. Current Opinion in Chemical Bioogyl 15: 129-136

Shaikhali J, Heiber I, Seidel T, Stroher E, Hiltscher H, Birkmann S, Dietz K-J and Baier M (2008) The redox-sensitive transcription factor Rap2.4a controls nuclear expression of 2-Cys peroxiredoxin A and other chloroplast antioxidant enzymes. BMC Plant Biology 8: 48

Shi YJ, Lan F, Matson C, Mulligan P, Whetstine JR, Cole PA, Casero RA and Shi Y (2004) Histone demethylation mediated by the nuclear arnine oxidase homolog LSD1. Cell 119: 941-953

Spedaletti V, Polticelli F, Capodaglio V, Schinina ME, Stano P, Federico R and Tavladoraki P (2008) Characterization of a lysine-specific histone demethylase from Arabidopsis thaliana. Biochemistry 47: 4936-4947

Spoel SH, Tada Y and Loake GJ (2010) Post-translational protein modification as a tool for transcription reprogramming. New Phytologist 186: 333-339

Sridha S and Wu K (2006) Identification of AtHD2C as a novel regulator of abscisic acid responses in Arabidopsis. Plant Journal 46: 124-133

Stamler JS, Singel DJ and Loscalzo J (1992) Biochemistry of nitric oxide and its redoxactivated forms. Science 258: 1898-1902

Stockinger EJ, Mao Y, Regier MK, Triezenberg SJ and Thomashow MF (2001) Transcriptional adaptor and histone acetyltransferase proteins in Arabidopsis and their interactions with CBF1, a transcriptional activator involved in cold-regulated gene expression. Nucleic Acids Research 29: 1524-1533

Strahl BD and Allis CD (2000) The language of covalent histone modifications. Nature 403: $41-45$

Sugiyama N, Nakagami H, Mochida K, Daudi A, Tomita M, Shirasu K and Ishihama Y (2008) Large-scale phosphorylation mapping reveals the extent of tyrosine phosphorylation in Arabidopsis. Molecular System Biology 4

Sung SB, He YH, Eshoo TW, Tamada Y, Johnson L, Nakahigashi K, Goto K, Jacobsen SE and Amasino RM (2006) Epigenetic maintenance of the vernalized state in Arabidopsis thaliana requires LIKE HETEROCHROMATIN PROTEIN 1. Nature Genetics 38: 706-710

Tada Y, Spoel SH, Pajerowska-Mukhtar K, Mou Z, Song J, Wang C, Zuo J and Dong X (2008) Plant immunity requires conformational charges of NPR1 via S-nitrosylation and thioredoxins. Science 321: 952-956

Taverna SD, Li H, Ruthenburg AJ, Allis CD and Patel DJ (2007) How chromatin-binding modules interpret histone modifications: lessons from professional pocket pickers. Nature Structiral \& Molecular Biology 14: 1025-1040

Teige M, Scheikl E, Eugelm T, Doczi R, Ichimura K, Shinozaki K, Dangl J and Hirt H (2004) The MKK2 pathway mediates cold and salt stress signaling in Arabidopsis. Molecular Cell 15: 141-152

Tian L and Chen ZJ (2001) Blocking histone deacetylation in Arabidopsis induces pleiotropic effects on plant gene regulation and development. Proceedings of the National Academy of Sciences of the United States of America 98: 200-205 
Tian L, Fong MP, Wang JJ, Wei NE, Jiang H, Doerge RW and Chen ZJ (2005) Reversible histone acetylation and deacetylation mediate genome-wide, promoter-dependent and locus-specific changes in gene expression during plant development. Genetics 169: 337-345

Tian L, Wang J, Fong MP, Chen M, Cao H, Gelvin SB and Chen ZJ (2003) Genetic control of developmental changes induced by disruption of Arabidopsis histone deacetylase 1 (AtHD1) expression. Genetics 165: 399-409

Tör M, Lotze MT and Holton N (2009) Receptor-mediated signalling in plants: molecular patterns and programmes. Journal of Experimental Botany 60: 3645-3654

Trujillo M and Shirasu K (2010) Ubiquitination in plant immunity. Current Opinion in Plant Biology 13: 402-408

Tsukada Y, Fang J, Erdjument-Bromage H, Warren ME, Borchers CH, Tempst P and Zhang $\mathrm{Y}$ (2006) Histone demethylation by a family of JmjC domain-containing proteins. Nature 439: 811-816

Turck F, Roudier F, Farrona S, Martin-Magniette ML, Guillaume E, Buisine N, Gagnot S, Martienssen RA, Coupland G and Colot V (2007) Arabidopsis TFL2/LHP1 specifically associates with genes marked by trimethylation of histone H3 lysine 27. Plos Genetics 3: 855-866

Umezawa T, Sugiyama N, Mizoguchi M, Hayashi S, Myouga F, Yamaguchi-Shinozaki K, Ishihama Y, Hirayama T and Shinozaki K (2009) Type 2C protein phosphatases directly regulate abscisic acid-activated protein kinases in Arabidopsis. Proceeding of the National Academy of Science of the United States of America 106: 1758817593

Vaillant I and Paszkowski J (2007) Role of histone and DNA methylation in gene regulation. Current Opinion in Plant Biology 10: 528-533

van Dijk K, Ding Y, Malkaram S, Riethoven JJM, Liu R, Yang JY, Laczko P, Chen H, Xia YN, Ladunga I, Avramova Z and Fromm M (2010) Dynamic changes in genome-wide histone $\mathrm{H} 3$ lysine 4 methylation patterns in response to dehydration stress in Arabidopsis thaliana. BMC Plant Biology 10

Varotto S, Locatelli S, Canova S, Pipal A, Motto M and Rossi V (2003) Expression profile and cellular localization of maize Rpd3-type histone deacetylases during plant development. Plant Physiology 133: 606-617

Vidal M, Buckley AM, Hilger F and Gaber RF (1990) Direct selection for mutants with increased $\mathrm{K}^{+}$transport in Saccharomyces cerevisiae. Genetics 125: 313-320

Vitecek J, Reinohl V and Jones RL (2008) Measuring NO production by plant tissues and suspension cultured cells. Molecular Plant 1: 270-284

Wang C, Gao F, Wu J, Dai J, Wei C and Li Y (2010) Arabidopsis putative deacetylase AtSRT2 regulates basal defense by supressing PAD4, EDS5 and SID2 expression. Plant Cell Physiology 51: 1291-1299

Wang X, Zhang Y, Ma QB, Zhang ZL, Xue YB, Bao SL and Chong K (2007) SKB1-mediated symmetric dimethylation of histone H4R3 controls flowering time in Arabidopsis. EMBO Journal 26: 1934-1941

Wang Y, Wysocka J, Sayegh J, Lee YH, Perlin JR, Leonelli L, Sonbuchner LS, McDonald CH, Cook RG, Dou Y, Roeder RG, Clarke S, Stallcup MR, Allis CD and Coonrod SA (2004) Human PAD4 regulates histone arginine methylation levels via demethylimination. Science 306: 279-283 
Wawer I, Bucholc M, Astier J, Anielska-Mazur A, Dahan J, Kulik A, Wyslouch-Cieszynska A, Zareba-Koziol M, Krzywinska E, Dadlez M, Dobrowolska G and Wendehenne D (2010) Regulation of Nicotiana tabacum osmotic stress-activated protein kinase and its cellular partner GAPDH by nitric oxide in response to salinity. Biochemical Journal 429: 73-83

Widmann C, Gibson S, Jarpe MB and Johnson GL (1999) Mitogen-Activated Protein Kinase: conservation of a three-kinase module from yeast to human. Physiological Reviews 79: $143-180$

Witte C-P, Keinath N, Dubiella U, Demoulière R, Seal A and Romeis T (2010) Tobacco Calcium-dependent Protein Kinases are differentially phosphorylated in vivo as part of a kinase cascade that regulates stress response. Journal of Biological Chemistry 285: 9740-9748

Wormuth D, Heiber I, Shaikali J, Kandlbinder A, Baier M and Dietz K-J (2007) Redox regulation and antioxidative defence in Arabidopsis leaves viewed from a systems biology perspective. Journal of Biotechnology 129: 229-248

Wu K, Malik K, Tian L, Brown D and Miki B (2000) Functional analysis of a RPD3 histone deacetylase homologue in Arabidopsis thaliana. Plant Molecular Biology 44: 167-176

Wu K, Tian L, Zhou C, Brown D and Miki B (2000) Repression of gene expression by Arabidopsis HD2 hitone deacetylases. Plant Journal 34: 241-247

Xiong T-C, Bourque S, Lecourieux D, Amelot N, Grat S, Brière C, Mazars C, Pugin A and Ranjeva R (2006) Calcium signaling in plant cell organelles delimited by a double membrane. Biochimica et Biophysica Acta (BBA) - Molecular Cell Research 1763: 1209-1215

Yan D, Zhang Y, Niu L, Yuan Y and Cao X (2007) Identification and characterization of two closely related histone $\mathrm{H} 4$ arginine 3 methyltransferases in Arabidopsis thaliana. Biochemical Journal 408: 113-121

Yap Y-K, Kodama Y, Waller F, Chung KM, Ueda H, Nakamura K, Oldsen M, Yoda H, Yamaguchi $Y$ and Sano H (2005) Activation of a novel transcription factor through phosphorylation by WIPK, a wound-induced mitogen-activated protein kinase in tobacco plants. Plant Physiology 139: 127-137

Yasuda M, Ishikawa A, Jikumaru Y, Seki M, Umezawa T, Asami T, Maruyama-Nakashita A, Kudo T, Shinozaki K, Yoshida S and Nakashita H (2008) Antagonistic interaction between systemic acquired resistance and the abscisic acid-mediated abiotic stress response in Arabidopsis. Plant Cell 20: 1678-1692

Yoo CY, Miura K, Jin JB, Lee J, Park HC, Salt DE, Yun DJ, Bressan RA and Hasegawa PM (2006) SIZ1 small ubiquitin-like modifier E3 ligase facilitates basal thermotolerance in Arabidopsis independent of salicylic acid. Plant Physiology 142: 1548-1558

Yoo S-D, Cho Y-H, Tena G, Xiong Y and Sheen J (2008) Dual control of nuclear EIN3 by bifurcate MAPK cascades in $\mathrm{C}_{2} \mathrm{H}_{4}$ signalling. Nature 451: 789-795

Zhang K, Sridhar VV, Zhu J, Kapoor A and Zhu JK (2007) Distinctive core histone posttranslational modification patterns in Arabisopsis thaliana. PLoS One 2: e1210

Zhang KL, Tang H, Huang L, Blankenship JW, Jones PR, Xiang F, Yau PM and Burlingame AL (2002) Identification of acetylation and methylation sites of histone $\mathrm{H} 3$ from chicken erythrocytes by high-accuracy matrix-assisted laser desorption ionizationtime-of-flight, matrix-assisted laser desorption ionization-postsource decay, and 
nanoelectrospray ionization tandem mass spectrometry. Analytical Biochemistry 306: 259-269

Zhang LW, Eugeni EE, Parthun MR and Freitas MA (2003) Identification of novel histone post-translational modifications by peptide mass fingerprinting. Chromosoma 112: 77-86

Zhang S and Klessig DF (1998) The tobacco wounding-activated mitogen-activated protein kinase is encoded by SIPK. Proceedings of the National Academy of Sciences 95: $7225-7230$

Zhang X, Germann S, Blus BJ, Khorasanizadeh S, Gaudin V and Jacobsen SE (2007) The Arabidopsis LHP1 protein colocalizes with histone H3 Lys27 trimethylation. Nature Structural \& Molecular Biology 14: 869-871

Zhang XY, Clarenz O, Cokus S, Bernatavichute YV, Pellegrini M, Goodrich J and Jacobsen SE (2007) Whole-genome analysis of histone H3 lysine 27 trimethylation in Arabidopsis. Plos Biology 5: 1026-1035

Zhang Y and Reinberg D (2001) Transcription regulation by histone methylation: interplay between different covalent modifications of the core histone tails. Genes \& Development 15: 2343-2360

Zhang ZL, Zhang SP, Zhang Y, Wang X, Li D, Li QL, Yue MH, Li Q, Zhang YE, Xu YY, Xue YBA, Chong K and Bao SL (2011) Arabidopsis floral initiator SKB1 confers high salt tolerance by regulating transcription and pre-mRNA splicing through altering histone H4R3 and small nuclear ribonucleoprotein LSM4 methylation. Plant Cell 23: 396-411

Zhou C, Zhang L, Duan J, Miki B and Wu K (2005) HISTONE DEACETYLASE 19 is involved in jasmonic acid and ethylene signalling of pathogen response in Arabidopsis. Plant Cell 17: 1196-1204 


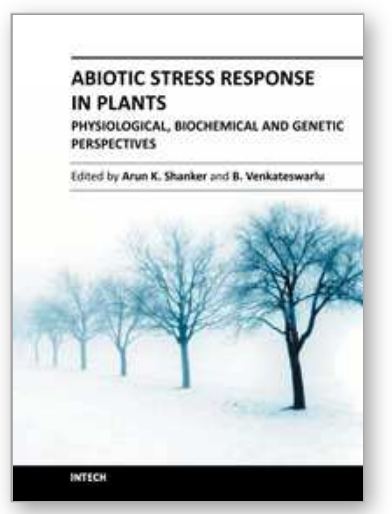

\author{
Abiotic Stress Response in Plants - Physiological, Biochemical \\ and Genetic Perspectives \\ Edited by Prof. Arun Shanker
}

ISBN 978-953-307-672-0

Hard cover, 346 pages

Publisher InTech

Published online 29, August, 2011

Published in print edition August, 2011

Plants, unlike animals, are sessile. This demands that adverse changes in their environment are quickly recognized, distinguished and responded to with suitable reactions. Drought, heat, cold and salinity are among the major abiotic stresses that adversely affect plant growth and productivity. In general, abiotic stress often causes a series of morphological, physiological, biochemical and molecular changes that unfavorably affect plant growth, development and productivity. Drought, salinity, extreme temperatures (cold and heat) and oxidative stress are often interrelated; these conditions singularly or in combination induce cellular damage. To cope with abiotic stresses, of paramount significance is to understand plant responses to abiotic stresses that disturb the homeostatic equilibrium at cellular and molecular level in order to identify a common mechanism for multiple stress tolerance. This multi authored edited compilation attempts to put forth an all-inclusive biochemical and molecular picture in a systems approach wherein mechanism and adaptation aspects of abiotic stress are dealt with. The chief objective of the book hence is to deliver state of the art information for comprehending the effects of abiotic stress in plants at the cellular level.

\title{
How to reference
}

In order to correctly reference this scholarly work, feel free to copy and paste the following:

Jennifer Dahan, Emmanuel Koen, Agnès Dutartre, Olivier Lamotte and Stéphane Bourque (2011). PostTranslational Modifications of Nuclear Proteins in the Response of Plant Cells to Abiotic Stresses, Abiotic Stress Response in Plants - Physiological, Biochemical and Genetic Perspectives, Prof. Arun Shanker (Ed.), ISBN: 978-953-307-672-0, InTech, Available from: http://www.intechopen.com/books/abiotic-stress-responsein-plants-physiological-biochemical-and-genetic-perspectives/post-translational-modifications-of-nuclearproteins-in-the-response-of-plant-cells-to-abiotic-stre1

\section{INTECH}

open science | open minds

\author{
InTech Europe \\ University Campus STeP Ri \\ Slavka Krautzeka 83/A \\ 51000 Rijeka, Croatia \\ Phone: +385 (51) 770447 \\ Fax: +385 (51) 686166 \\ www.intechopen.com
}

\author{
InTech China \\ Unit 405, Office Block, Hotel Equatorial Shanghai \\ No.65, Yan An Road (West), Shanghai, 200040, China \\ 中国上海市延安西路65号上海国际贵都大饭店办公楼 405 单元 \\ Phone: +86-21-62489820 \\ Fax: $+86-21-62489821$
}


(C) 2011 The Author(s). Licensee IntechOpen. This chapter is distributed under the terms of the Creative Commons Attribution-NonCommercialShareAlike-3.0 License, which permits use, distribution and reproduction for non-commercial purposes, provided the original is properly cited and derivative works building on this content are distributed under the same license. 